\title{
SPECIAL LINGUISTIC GLOSSARY - AN ANALYTICAL DESCRIPTIVE STUDY
}

http://dx.doi.org/10.47832/2757-5403.4-3.27

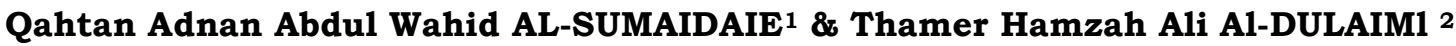

\begin{abstract}
:
The mind cannot imagine that any science shows enrichment without the need for this Because true science is a reaction to a scientific problem in society and a necessity to open what is closed to understand it, and scientific convergence between nations is one of the most important problems that need channels of communication that help in understanding the culture of the other and understanding the other. Our culture, We now live in a small world dominated by information technology and digital computers, and the communication process is very fast and easy, This undoubtedly makes the process of communication between communities very easy and gives a great demand for understanding the languages of others village that brings the distant closer and draws explicit features in the mind of society, and all of this needs a clarification of terms and keeping pace with their formations, and this understanding must be based on a special scientific perspective devoid of emotional inclination and cloaked in a scientific scarf,This understanding and perspective grows in an important angle in language as it is the image and mirror that reflects human culture. Language is the vessel of thought, and this language in our world is no longer confined to what is scattered on the peaks of the Arabian desert, and therefore dictionaries came to form important features of intellectual communication at the level of language and culture. And this art is authentic in languages, especially Arabic, and because of the flexibility of Arabic and its ability to accept the stranger in sound, morphology, and semantics, as it expanded to receive the ancient Arabizer, so it flaunted it with its originality to be an Arab or to wear the dress of the Arabic inflection and its significance, Flexibility of Arabic has developed with us as a lexical extension that helped accept the other, keep up with him and communicate with him without that at the expense of the origin. And the formation of scientific visions that help in rooting the linguistic link away from bias, and these special linguistic dictionaries are cultural formations that were limited to one linguistic color, and this keeps pace with the era of speed in

\footnotetext{
${ }^{1}$ Dr. , Sunni Endowment Diwan, Iraq, somiada82@gmail.com, https://orcid.org/0000-0003-4026-4628

${ }^{2}$ Dr. , Al-Karkh Second Directorate of Education, Iraq, thamrhmz73@gmail.com, https://orcid.org/0000-00028578-3133
} 
specialization and understanding terms away from stuffiness, repetition and chaos overlapping linguistic levels.

Key words: Industry, Term, Linguistic, Private Lexicon

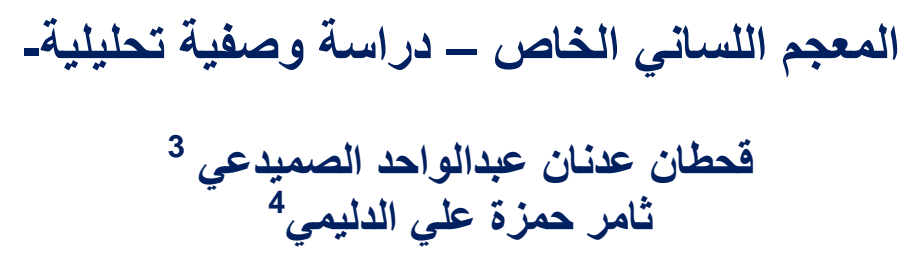

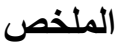

لا يمكن أن نتصور عقلا أن أي علم يظهر إثراء دون الحاجة إليه، فالعلم الحق إنما هو ردة

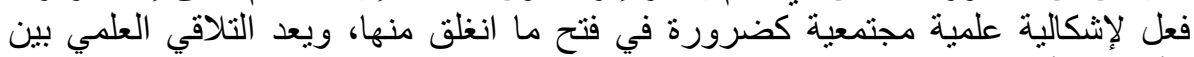

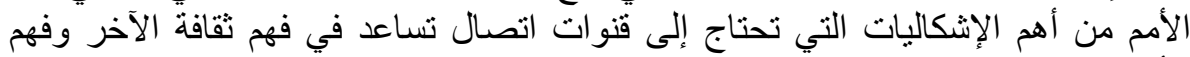

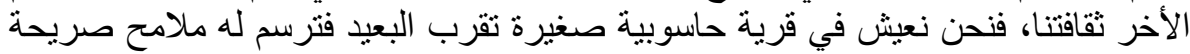

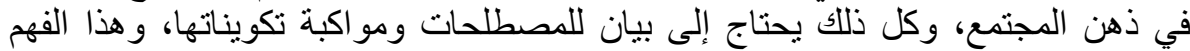

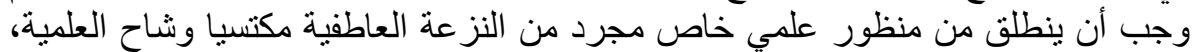

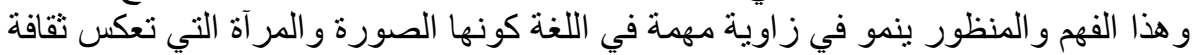

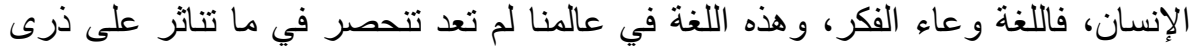

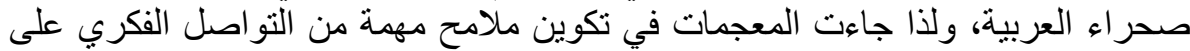

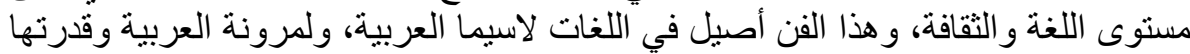

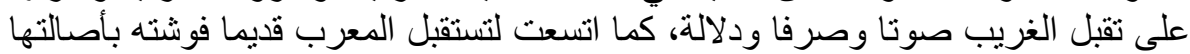

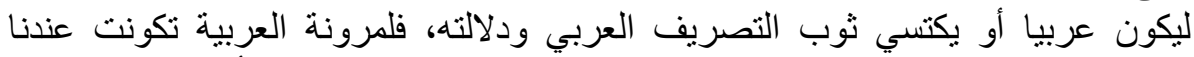

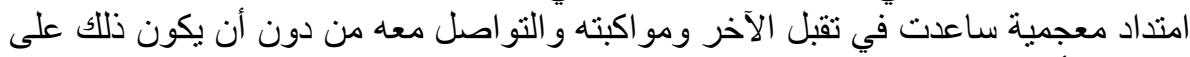

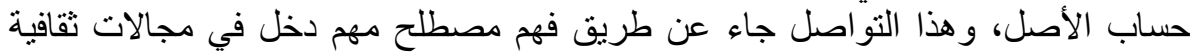

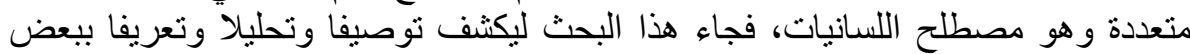

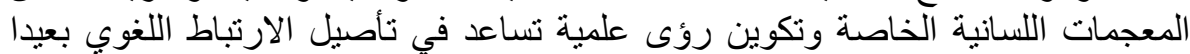

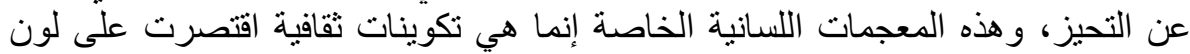

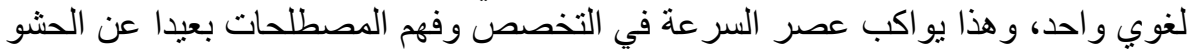

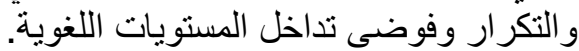
الكلمات المفتاحية: صناعة، المصطلح، اللساني، المعجم، الخاص. اللمان.
\end{abstract}

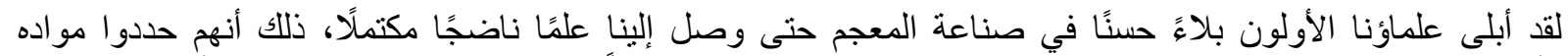

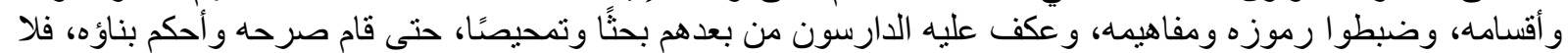

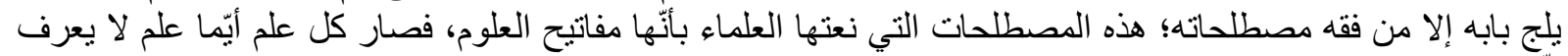

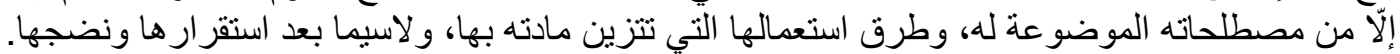

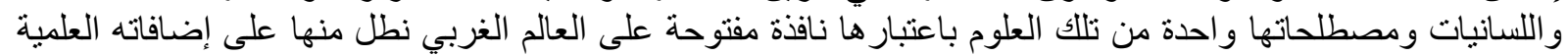
و والمعرفية. لقد أصبحت مقدار حاجة الدرس العربي لهذا العلم حاجة ماسة وملحة للإطلاع على المعرفة المعاصرة ومستلزماتها،

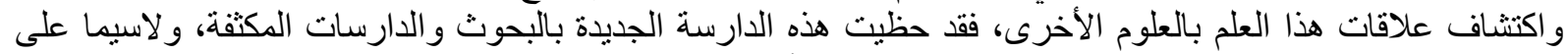

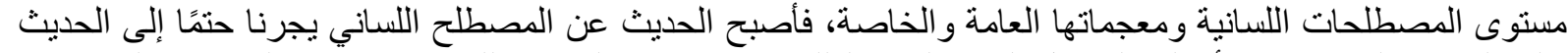
على المعاجم التي مادتها الأصلية المداخل المصطلحية؛ لذلك تنوعت فند عندا المعاجم اللسانية من حيث الوضع، و الترجمة. 


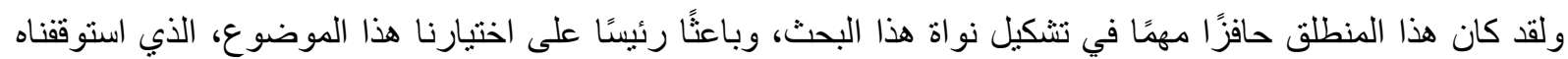

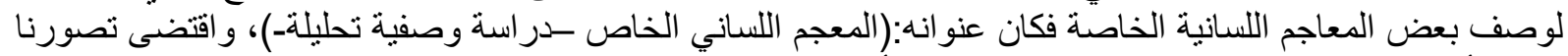

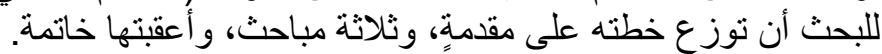
تكفّل المبحث الأول بِّل بيان صناعةً المصطلح اللساني في المعجم الخاص، وتناول مفهومي المصطلح، والمعجم اللساني

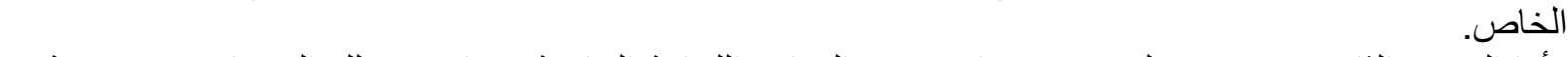
و أما المبحث الثاني: فخصصنه لوصف مقدمات بعض المعاجم اللسانية الخاصة، وما حوته تلاك المقدمات من منهجية في التأليف، أو الترجمة.

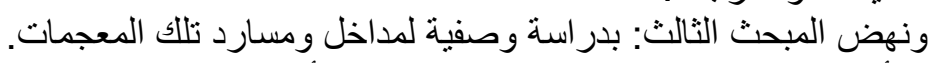

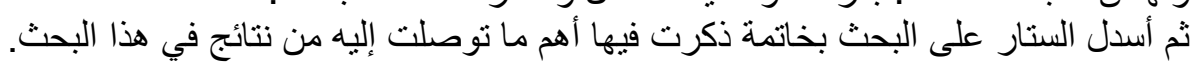

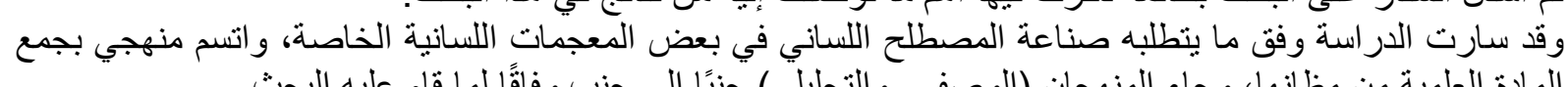

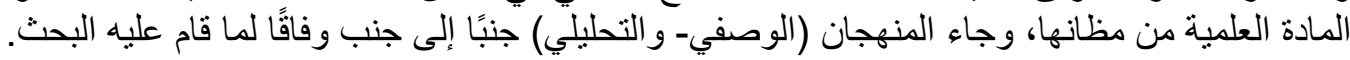

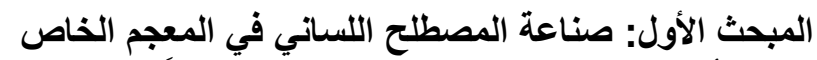

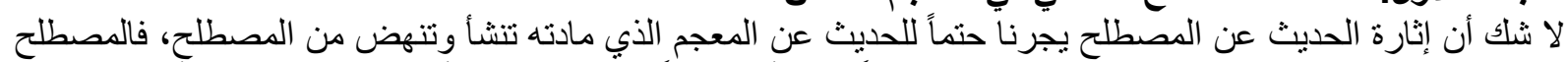

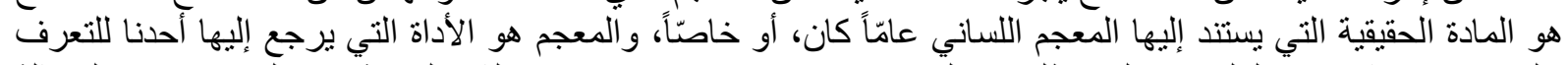

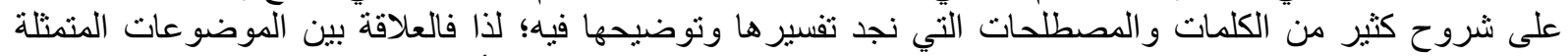
بالمصطلح اللساني و المعجم تلازمية فكل واحد منهما منوقف على الآخر. ينظر: (أسماء، 2013 /2014م، الصنات الصفحات

ومن هذا المنطلق لابد لنا أن نبدأ تمهيدنا هذا بتتاول مفهومي المصطلح، و المعجم اللساني الخاص بشيء من الإيضاح كل

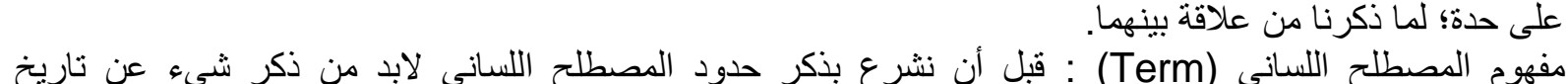

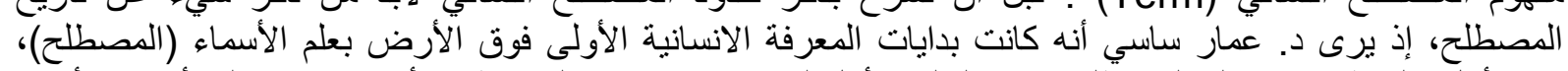

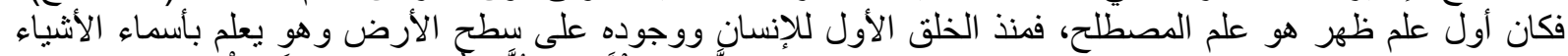

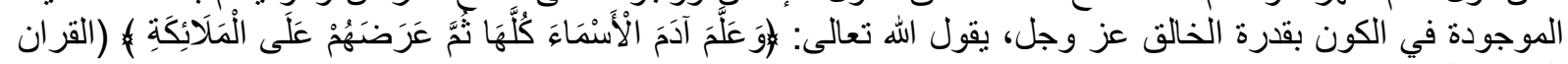

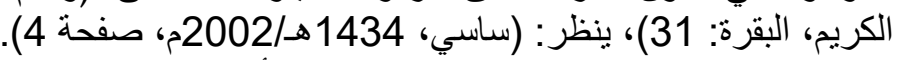

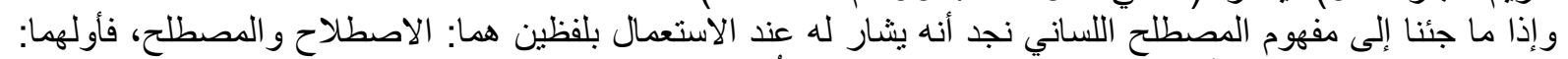

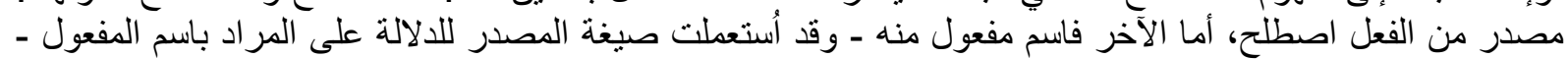

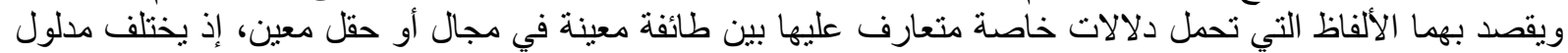

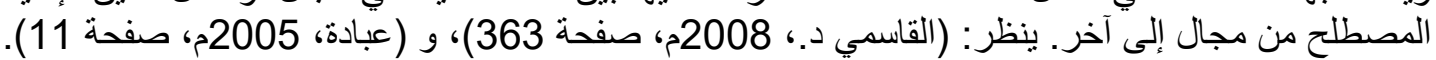

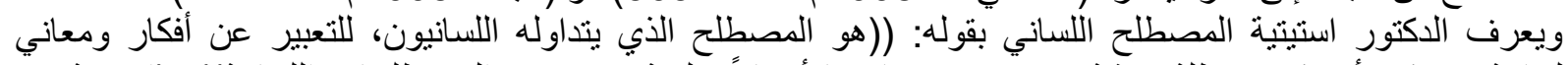

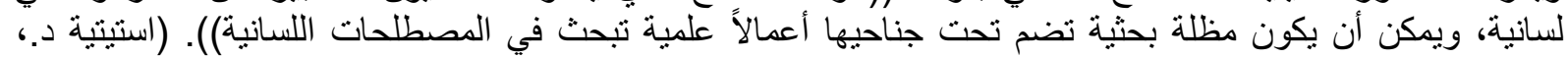

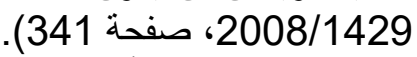

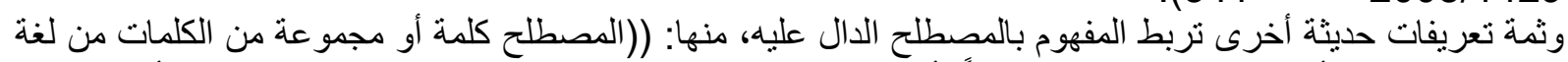

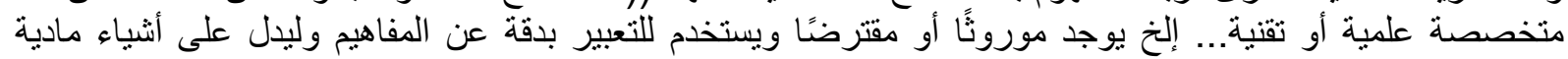

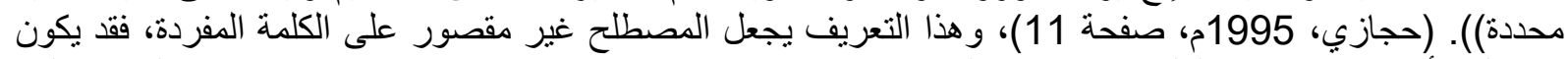

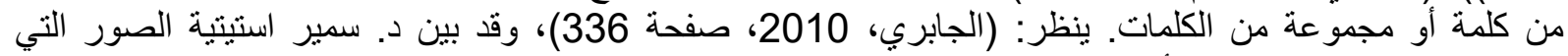

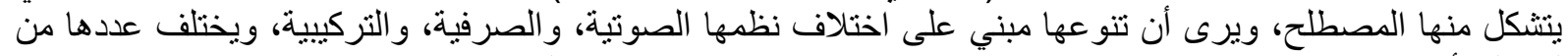

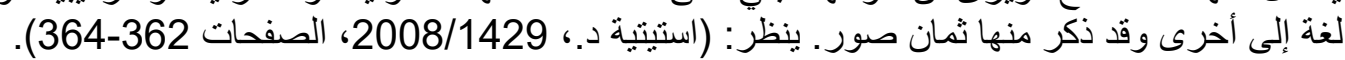

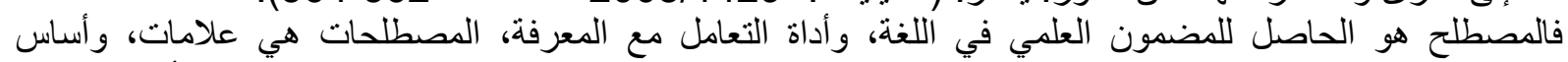

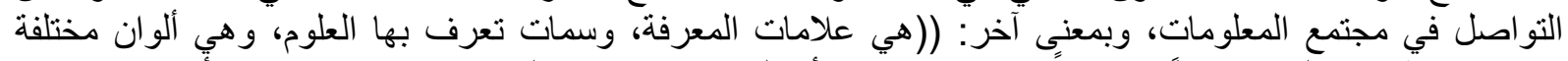

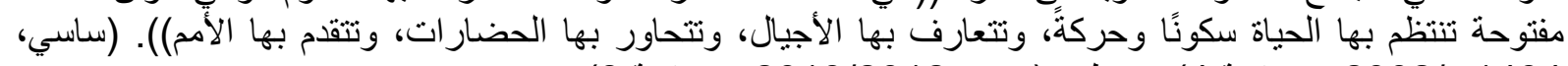

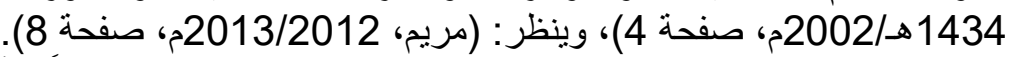

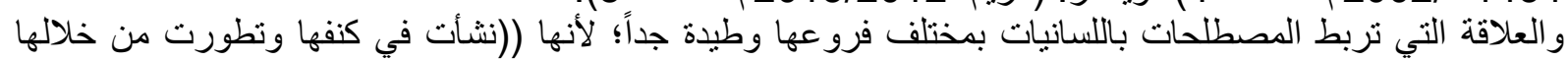

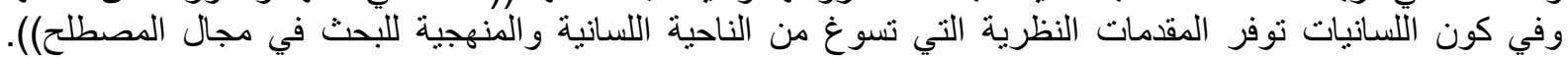

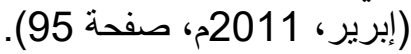

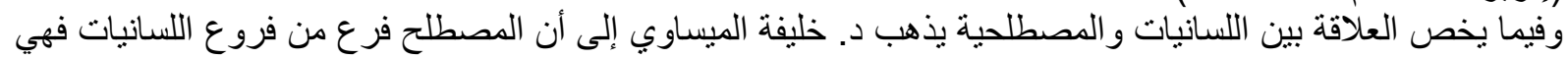

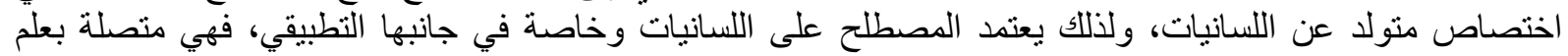


المعجمية والنظريات الدلالية وصناعة المعاجم ولسانيات المدونة واللغة المختصة. ينظر: (الميساوي، 1434هـ/2013م،

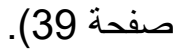

وترى الباحثة فريدة ديب أن الناظر إلى المصطلحات و اللسانيات يجد أن هناك علاقة تكاملية بينهما؛ لأنهما يتقاسمان

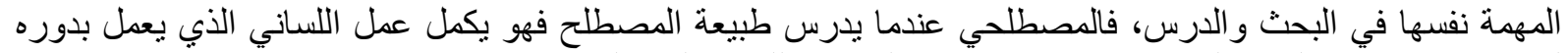
للإحاطة بموضوع المصطلح وفهمه وهو ما يحقق الوظيفة اللسانية لهذا المفهوم. ينظر : (ديب، 2013/2012م، صفحل

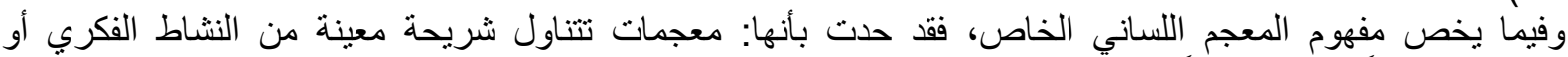

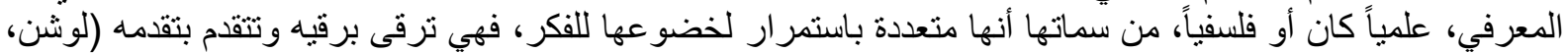

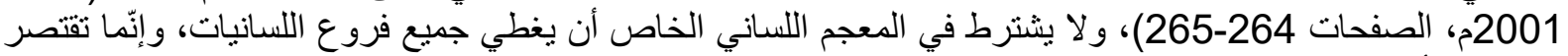

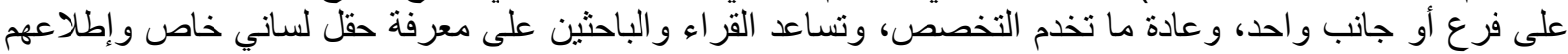

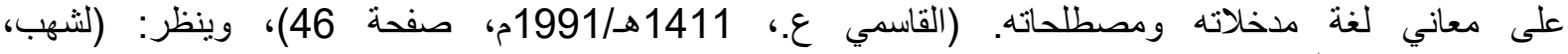
(70-69). 2011/2010م، الصفحان.

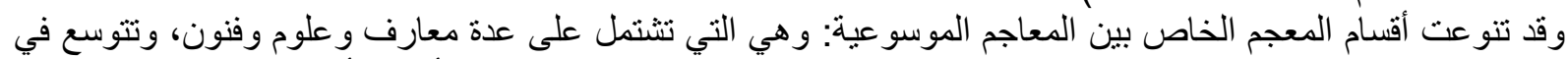

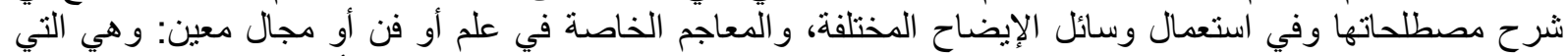

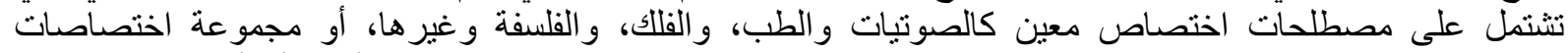

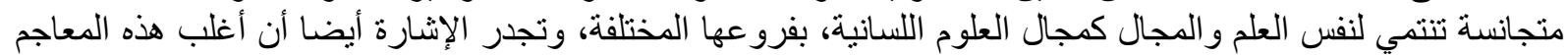

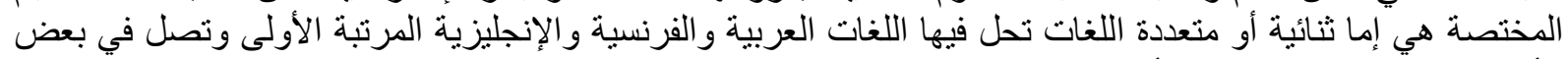

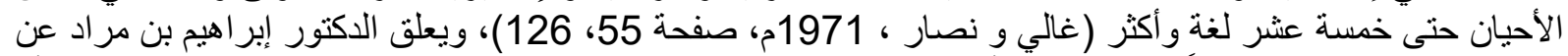

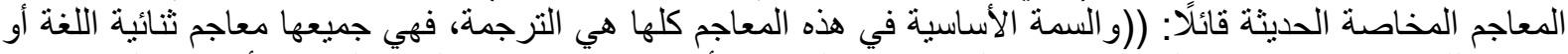

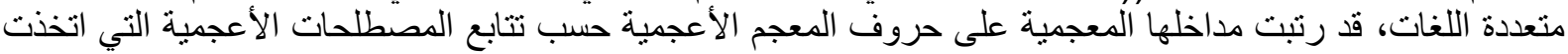

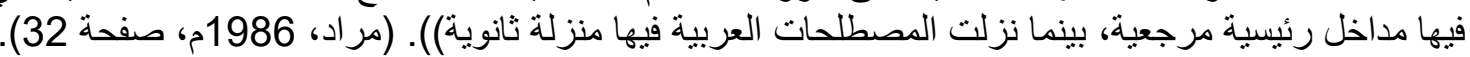

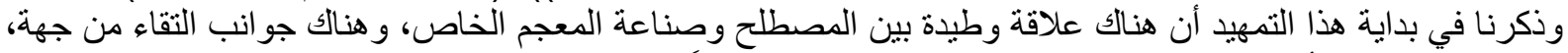

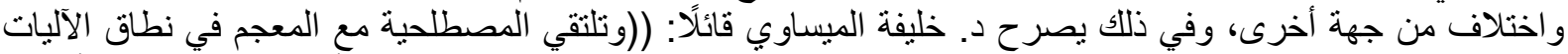

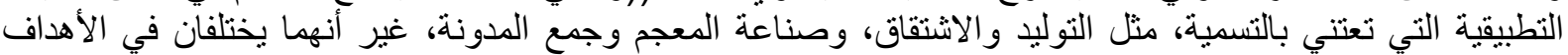

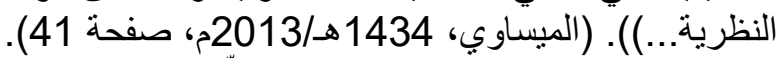

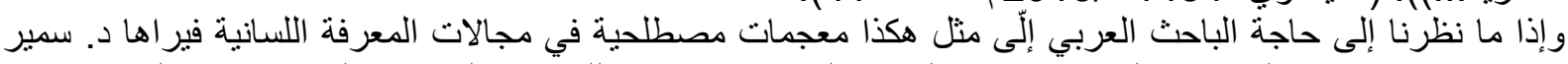

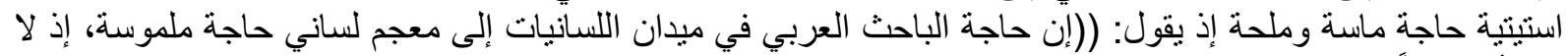

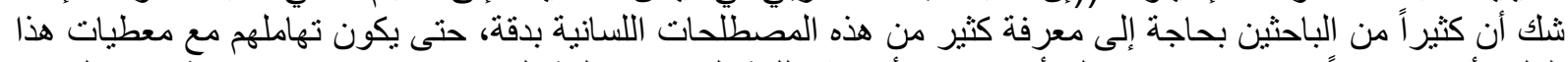

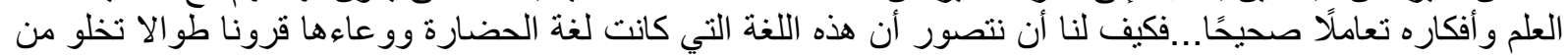

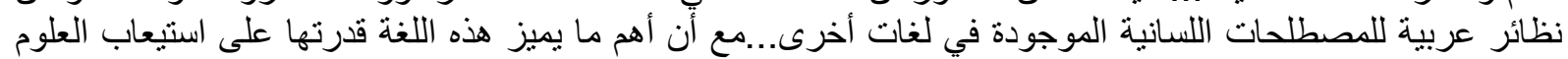

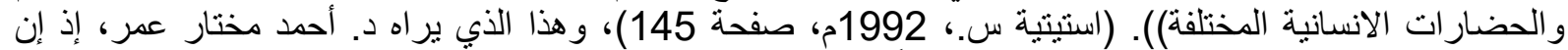

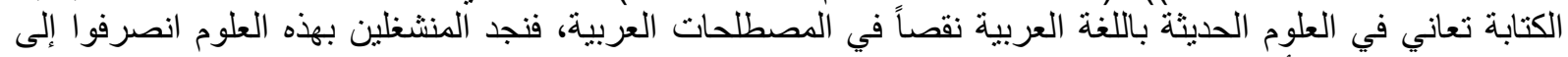

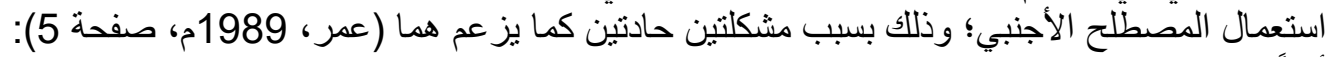

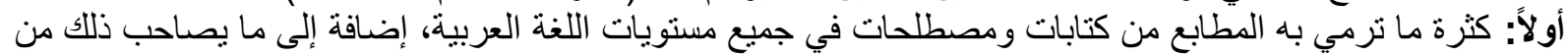

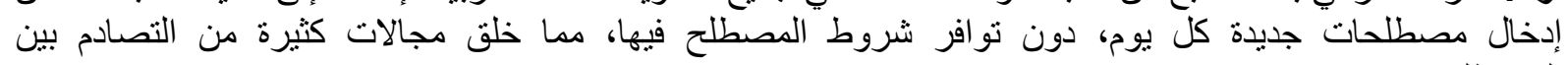

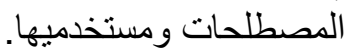

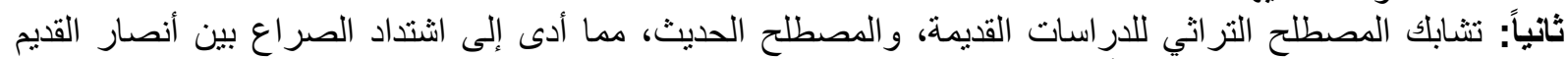

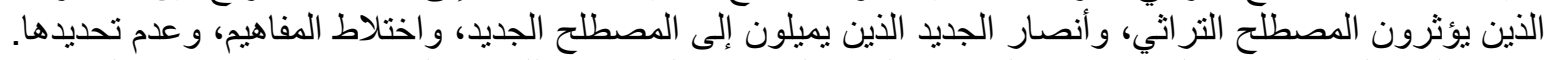

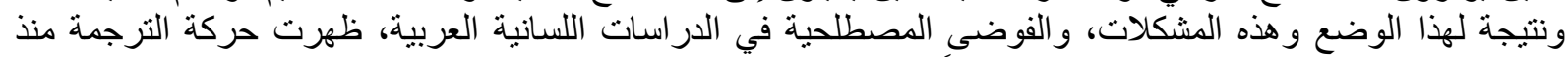

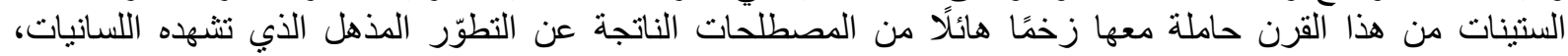

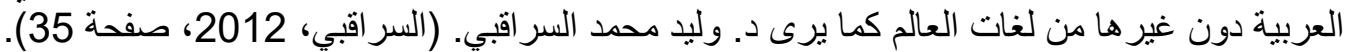

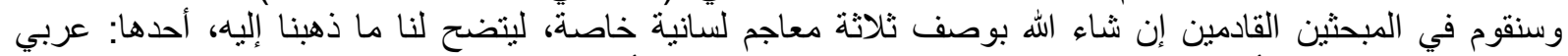

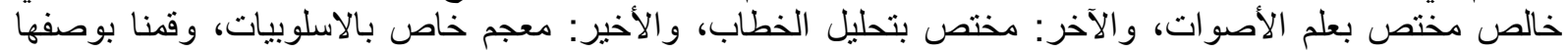
حسب قدمها من حيث الإخر اج الطباعي.

المبحث الثاني: وصف المقدمات لبعض المعاجم اللسانية الخاصة

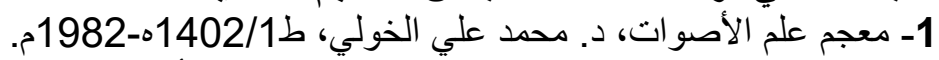

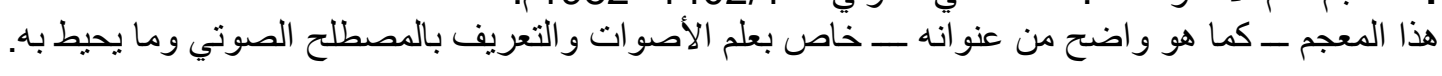




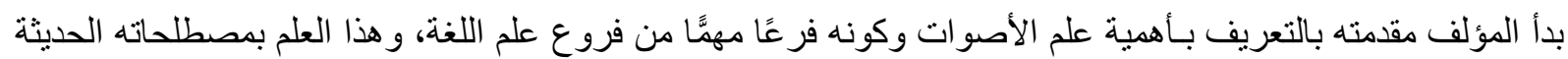

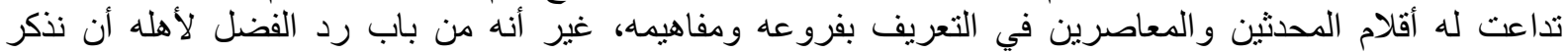

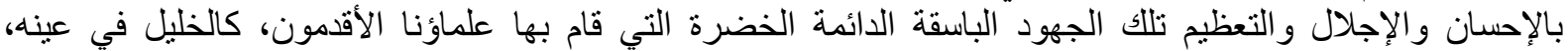

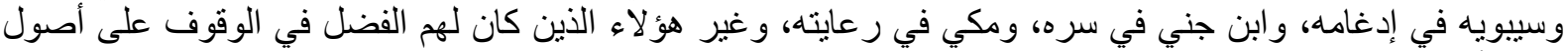

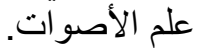

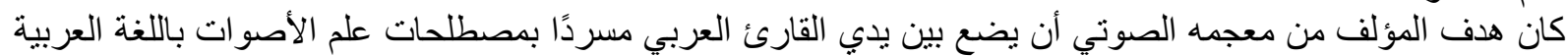

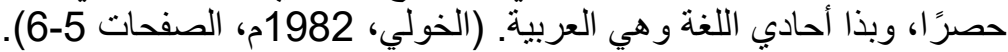

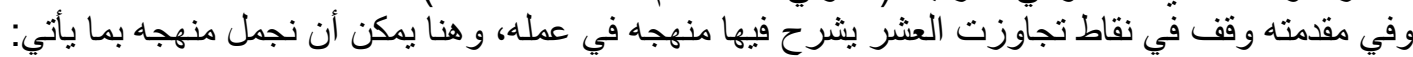

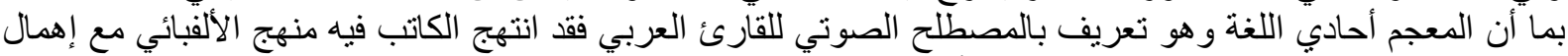

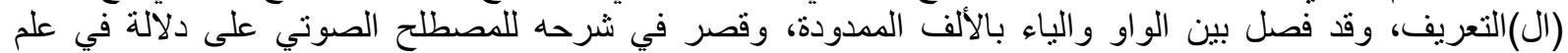

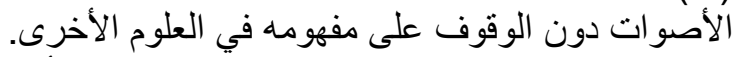

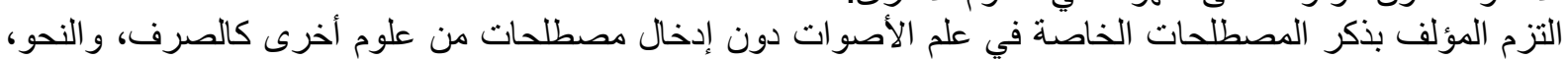

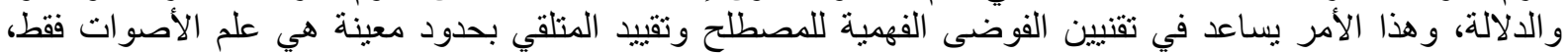
وكذللك قد نفع هذا المنهج للمؤلف ألّا يكون شرحه موسوعيا بل قد لا يتجاوز السطر أو في بعضها ثلاثة أسطر في أغلب الأحيان.

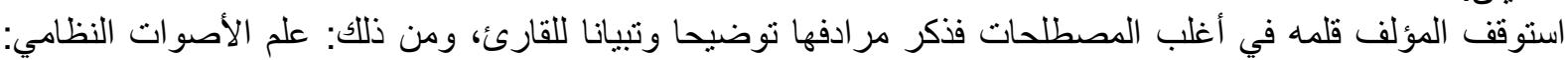

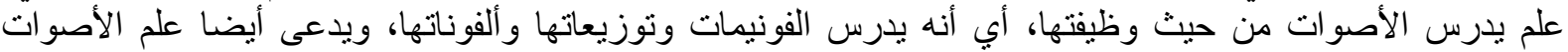

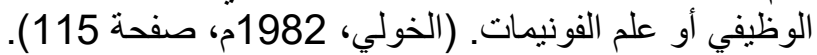

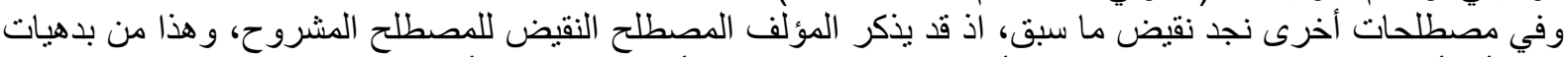

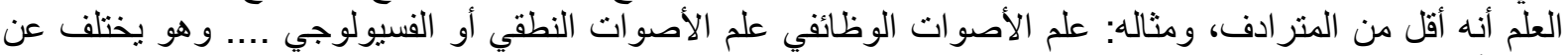

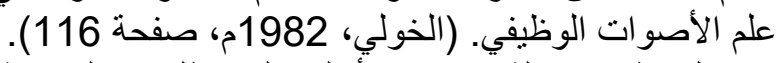

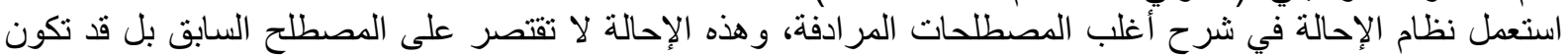

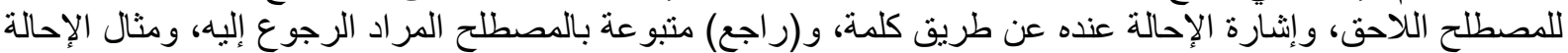

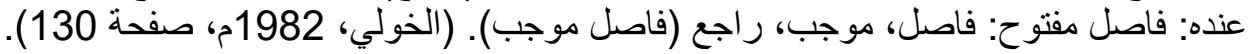

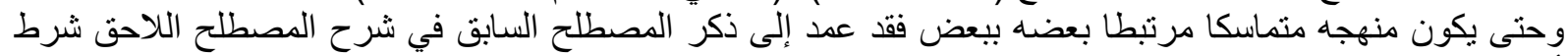

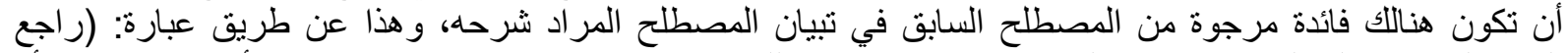

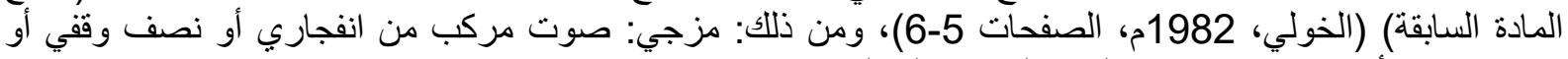

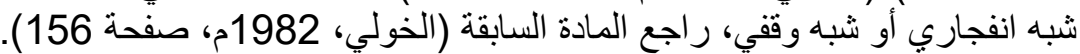

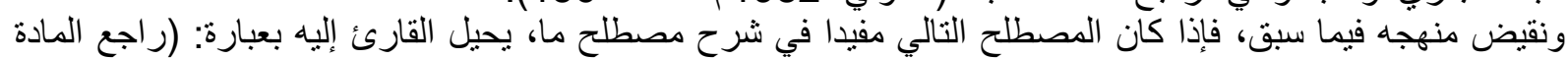

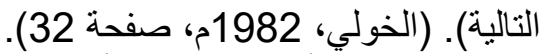
و على الرغم من أن معجمه كان أحادي اللغة (العربية) غير أنه نوسع في الأمثلة التوضيحة، فأخذ من الانكليزية و وغير ها

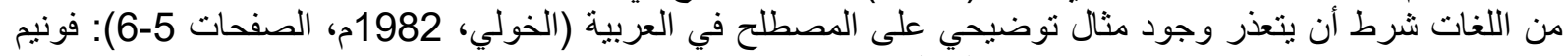

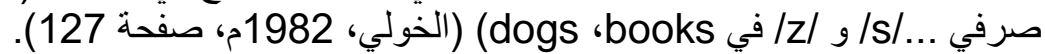

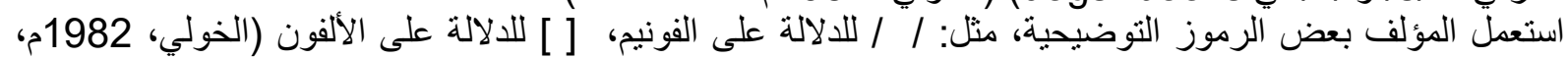

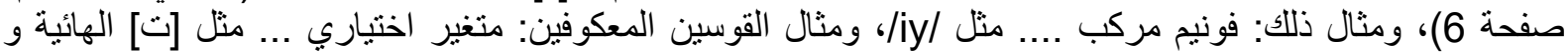

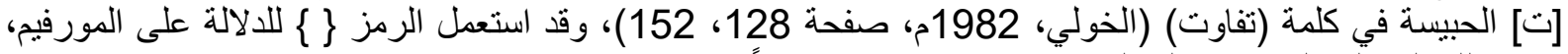

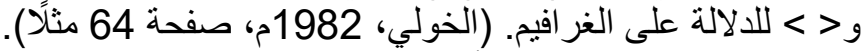

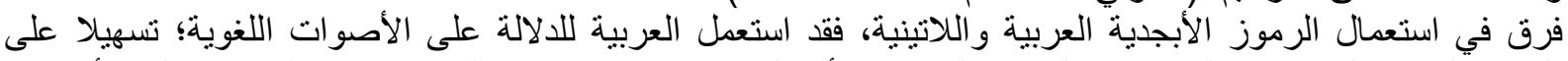

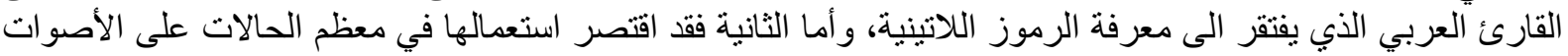

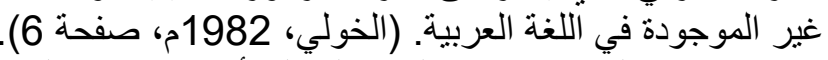

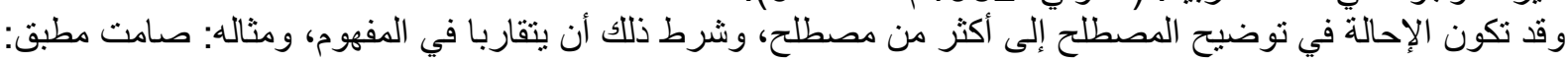

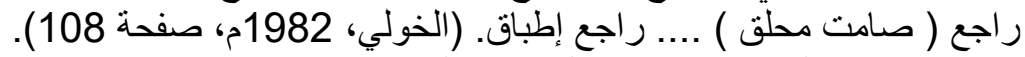

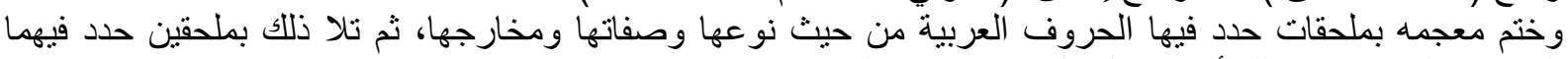

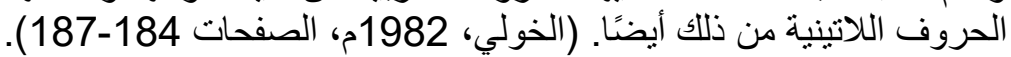
2- معجم تحليل الخطاب، باشراف: باتثريك شنارودو - ودومينيك منغنو، ترجمة: عبد القادر المهيري و حمادي صمّود/2008م. هو معجم تحليل الخطاب المترجم من اللغة الفرنسية إلى اللغة العربية عن Dictionnaire D'analyse du) Discours) 
DominiqueMangueneau .(16-15 صدر في طبعته الأولى سنة 2002م عن دار سوي edition du seuil الفرنسية، وقد أثرف على ترجمته المترجمان

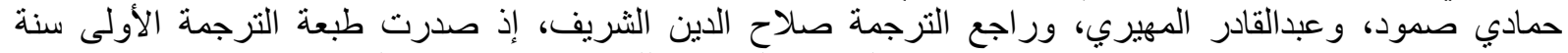

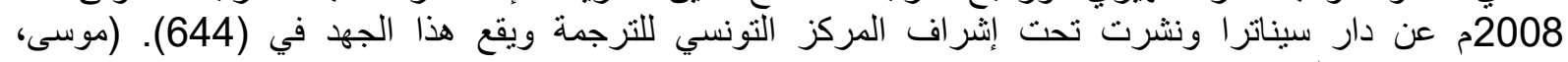

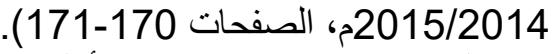

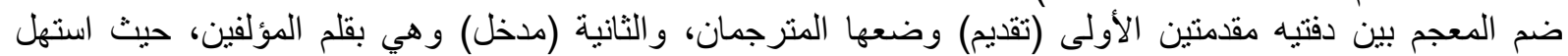

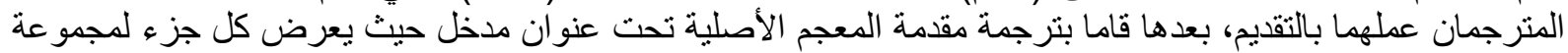

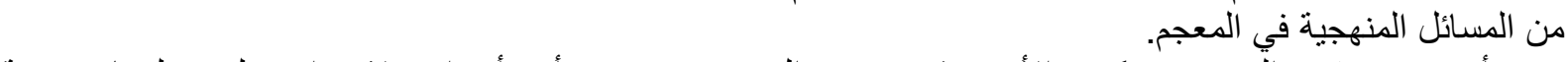

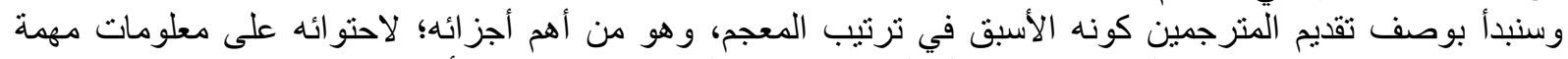

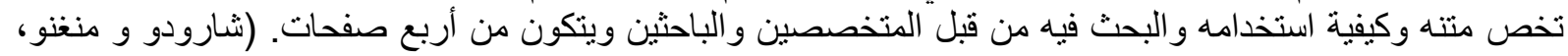

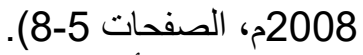

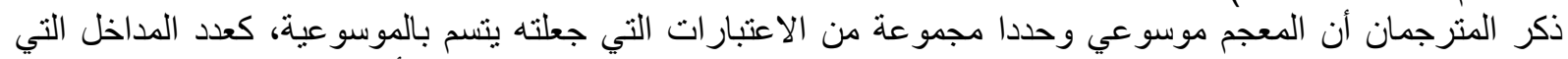

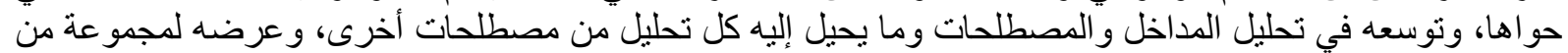

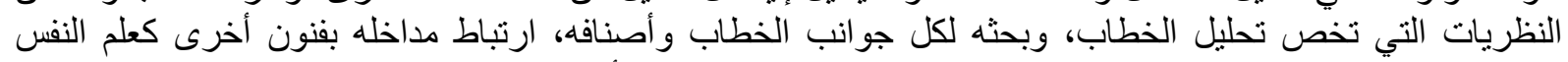

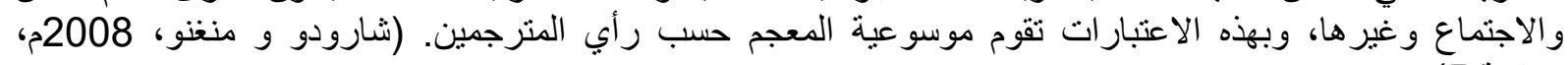

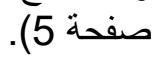

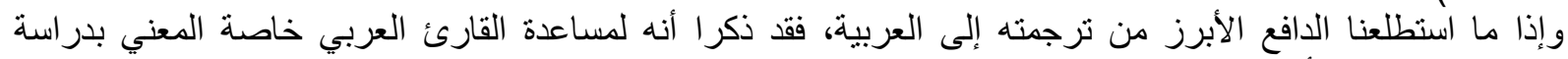

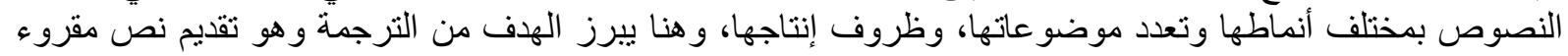

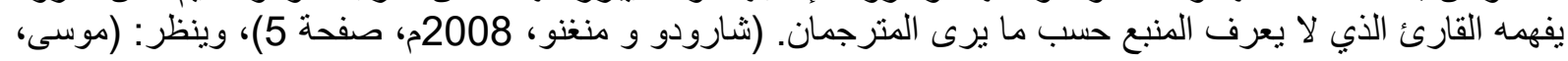

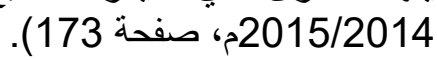
ومع انبهار هما بالعمل الغربي ودقته نجدهم يصرحان على ضرورة التوقف عند النص العربي والإمعان فيه؛ وذلك لونعوبة النص الأجنبي.

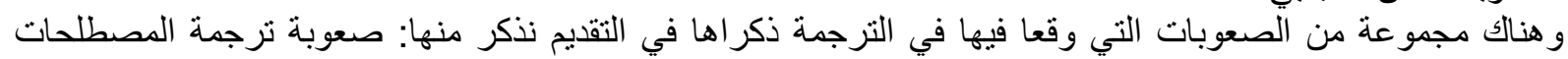

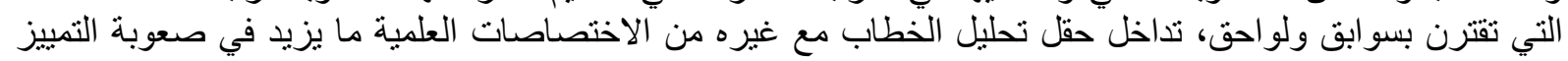

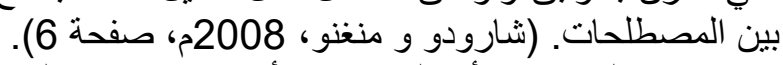

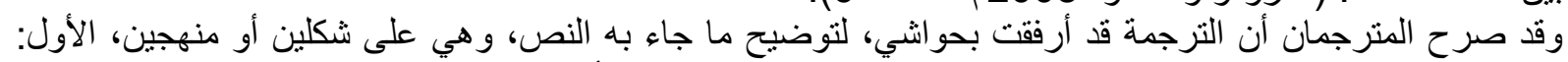

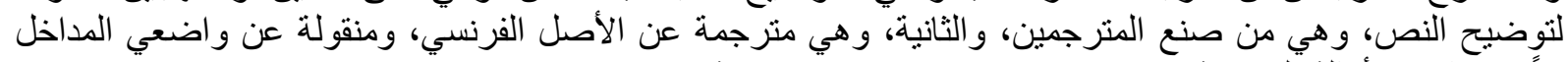

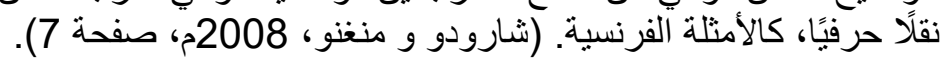

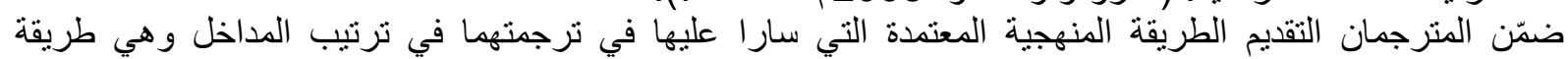

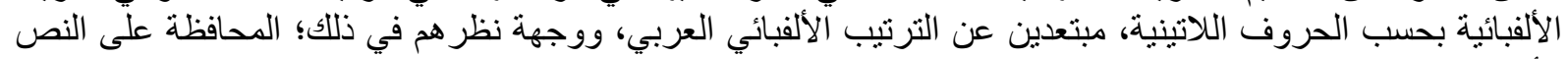

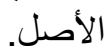

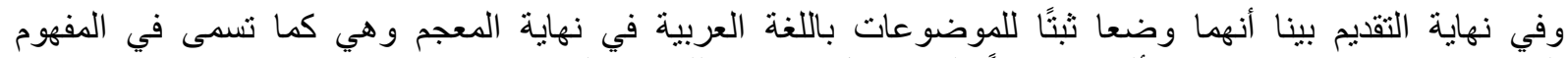

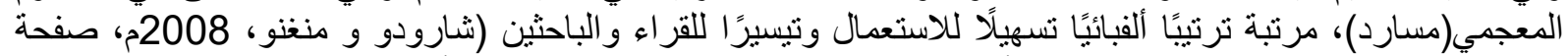

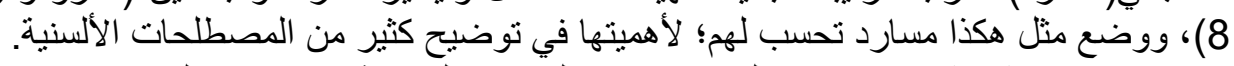

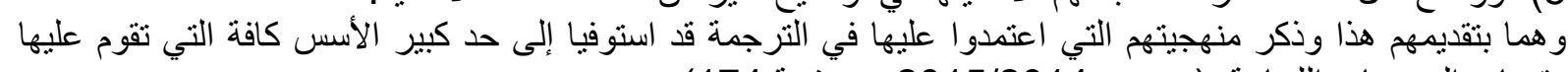

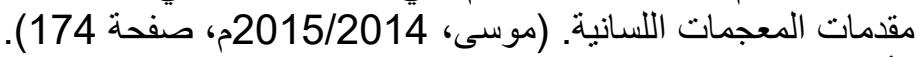

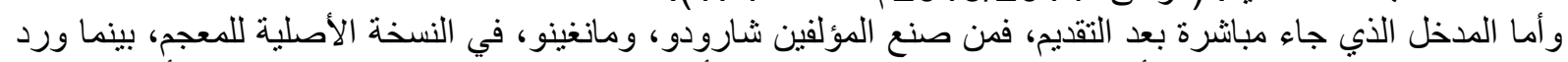

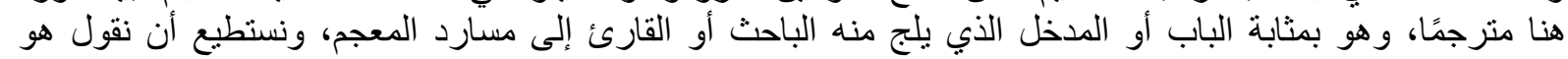

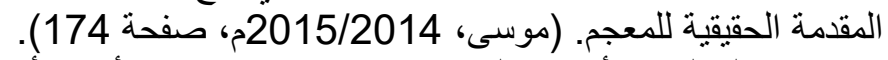

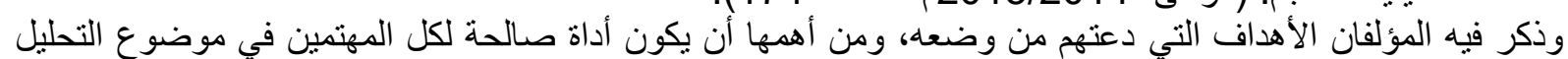

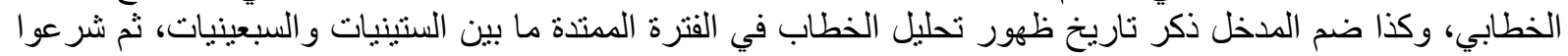

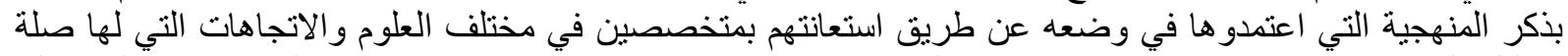

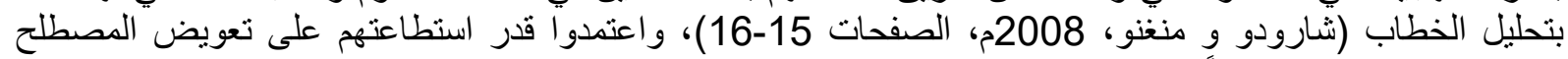

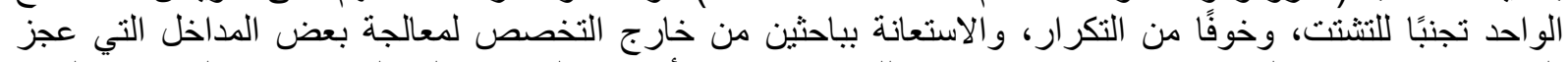

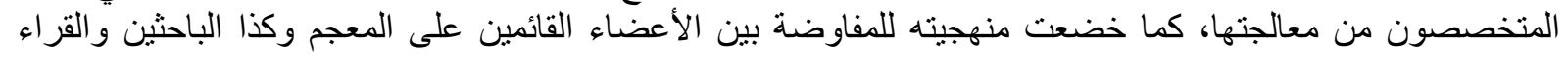

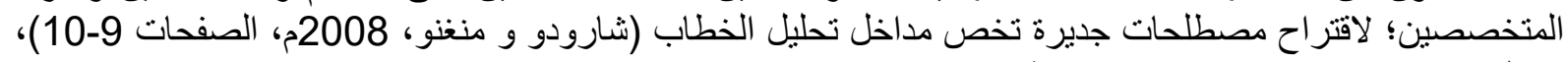

وينظر: (موسى، 2015/2014م، صفحة 175). 


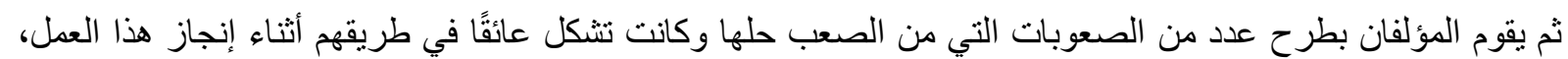

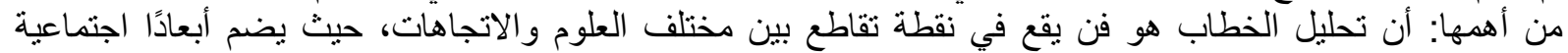

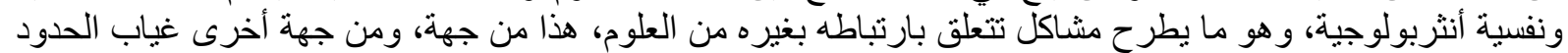

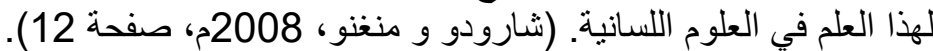

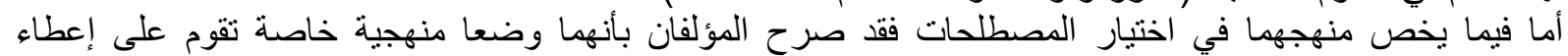

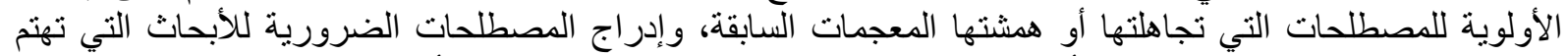

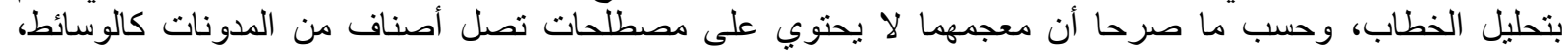

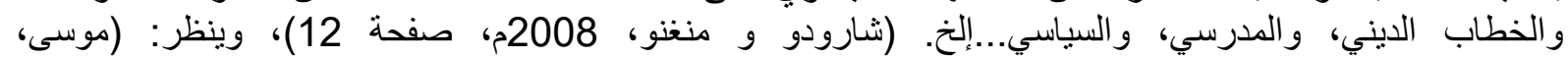

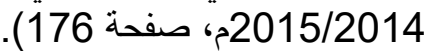

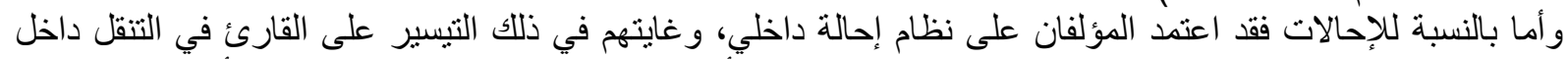

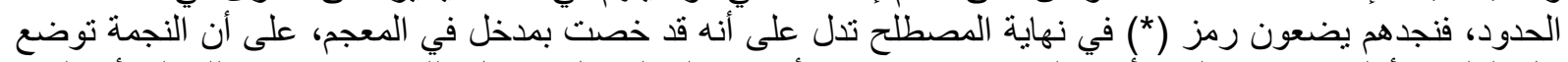

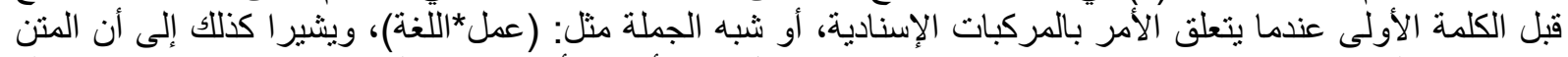

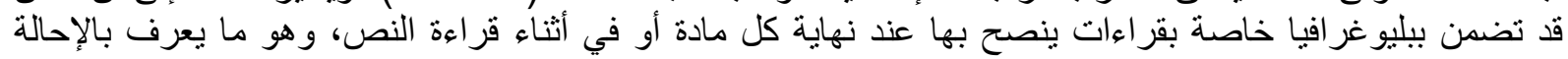

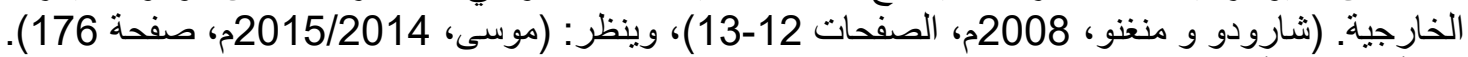

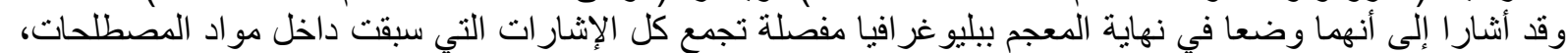

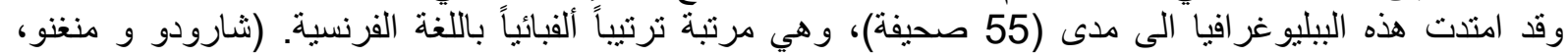

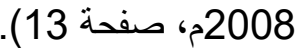

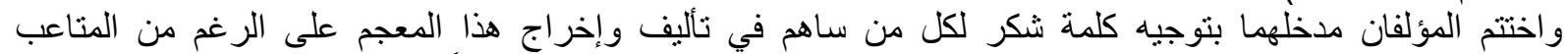

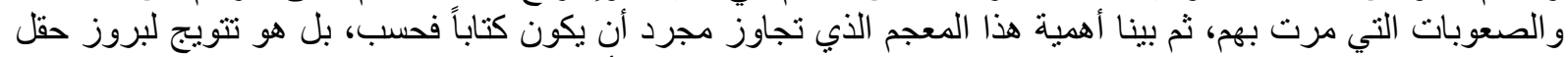

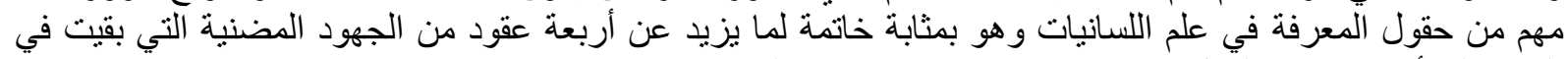

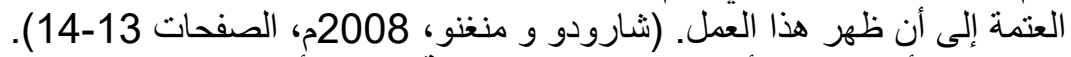

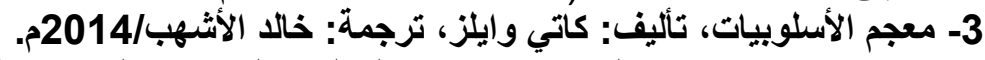

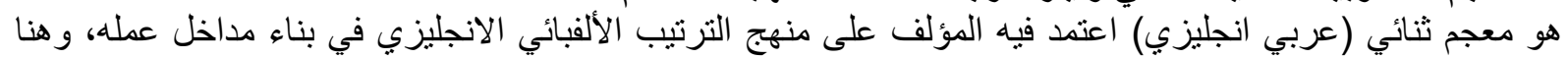

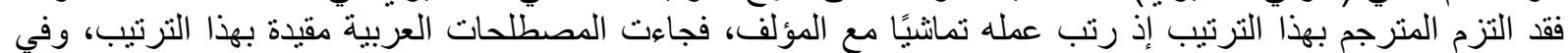

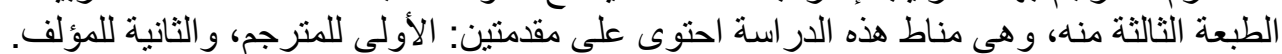

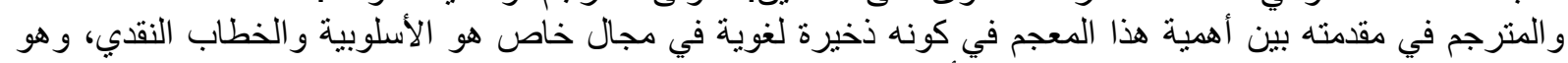

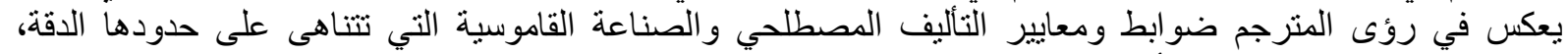

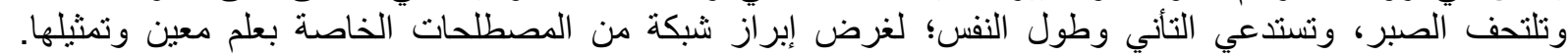

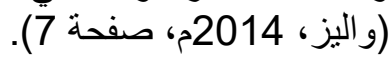

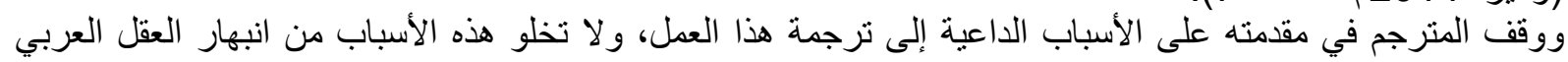

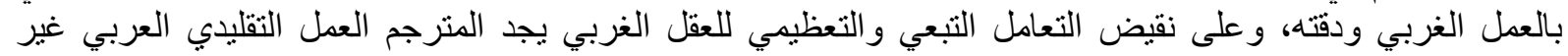

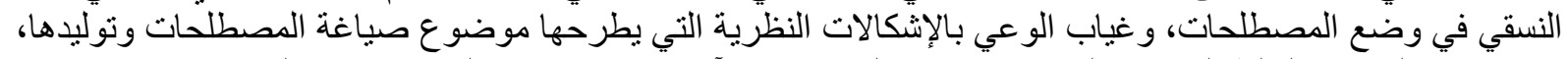

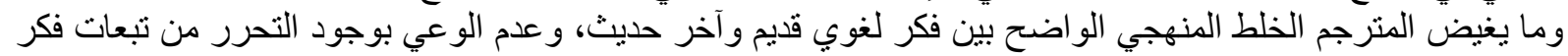

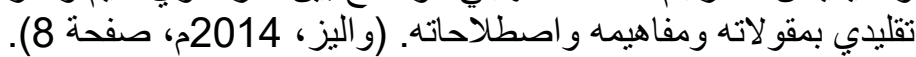

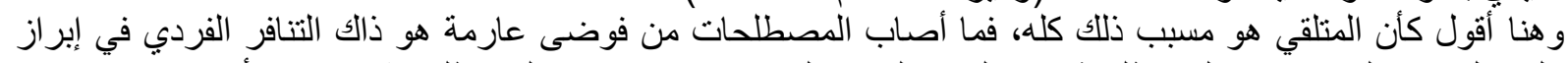

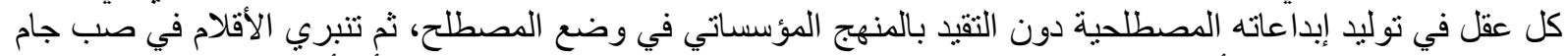

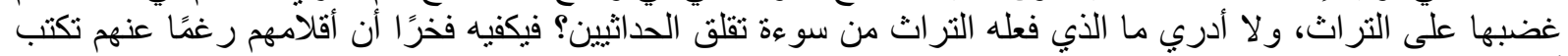

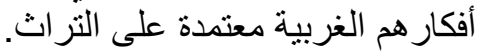

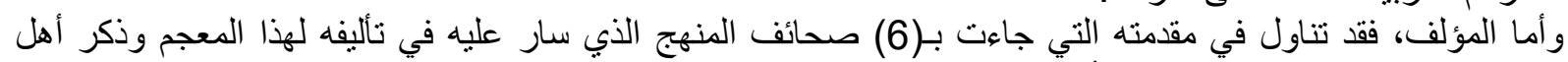

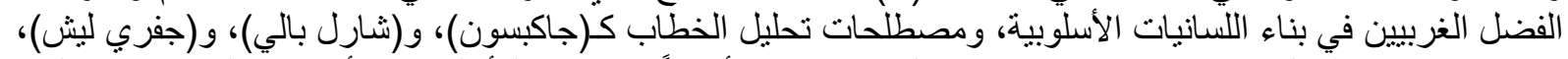

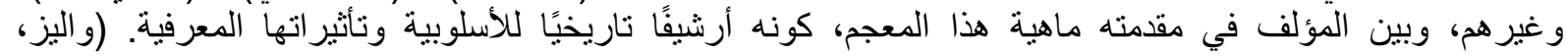

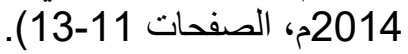

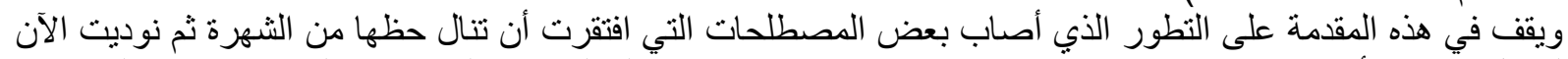

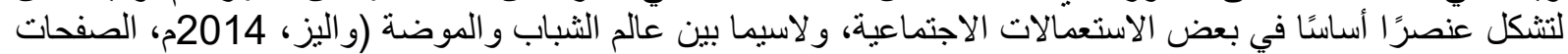

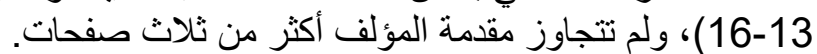

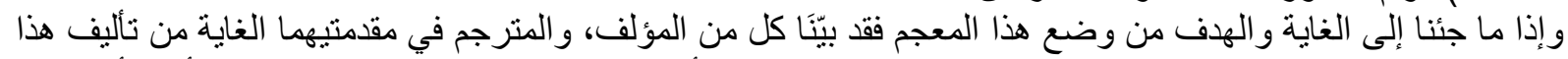

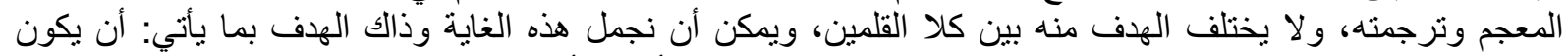

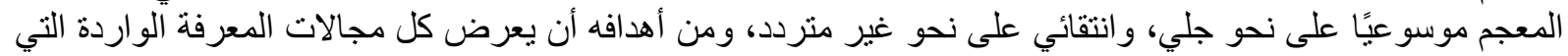




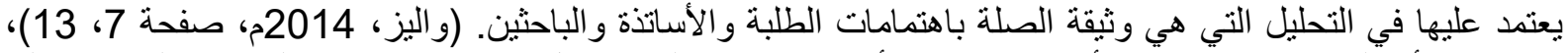

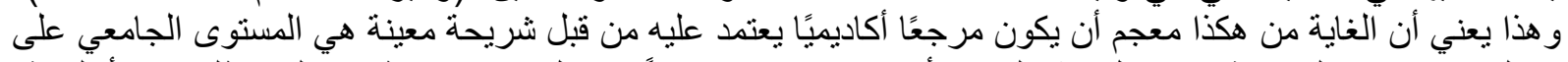

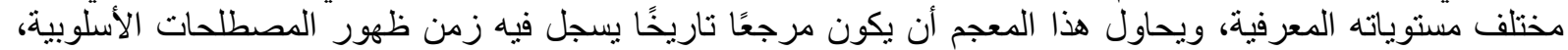

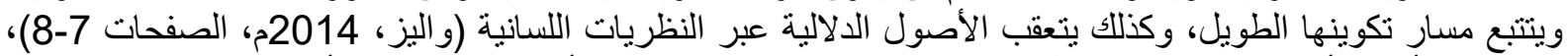

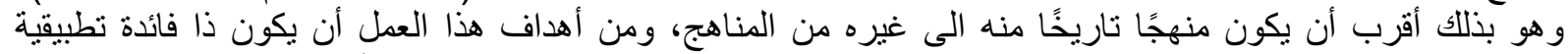

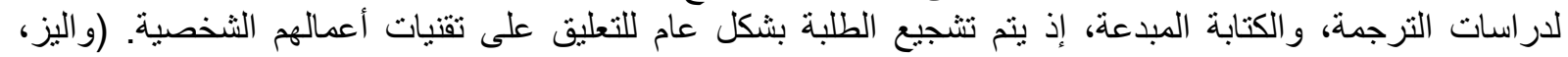
2014م، صفحة 14). 
المبحث الثالث: وصف مداخلها ومساردها

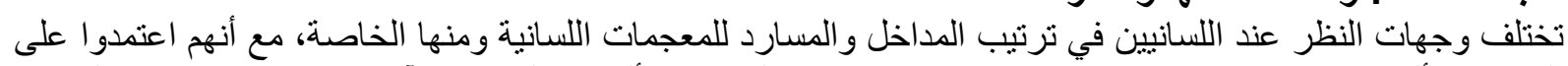

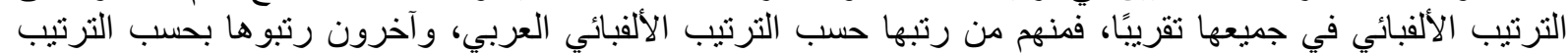

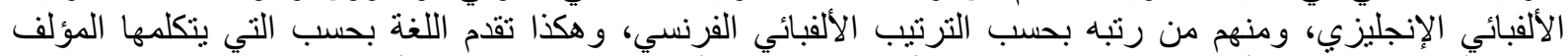

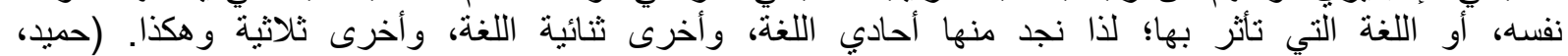

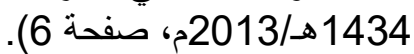
و هناك نرنيب آخر لمداخل تنلك المعجمات على حسب التب الترنيب الموضوعي، والترنتب المفهومي ينظر: (خسارة،

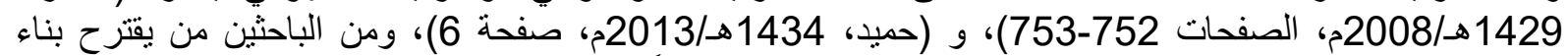

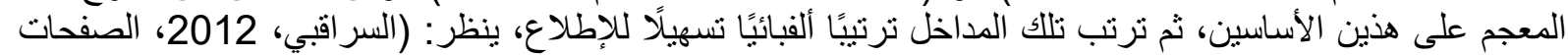

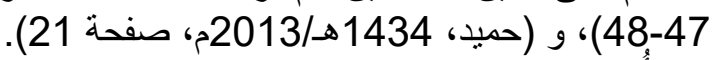

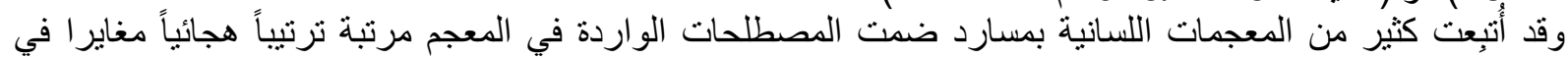

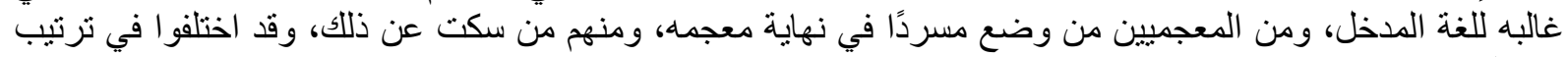

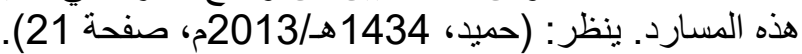

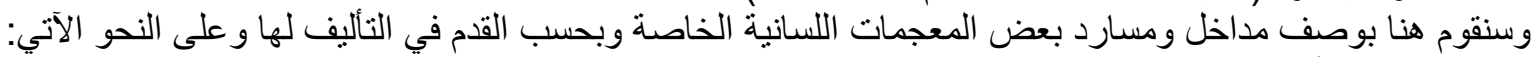
1- معجم علم الأصوات، د. هـ محمد على ومدي الخولي.

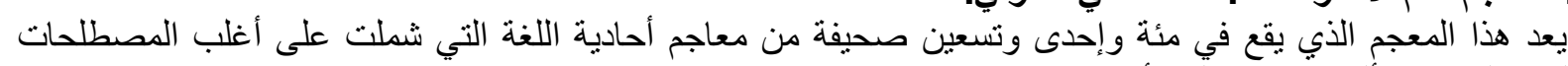

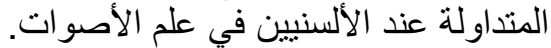

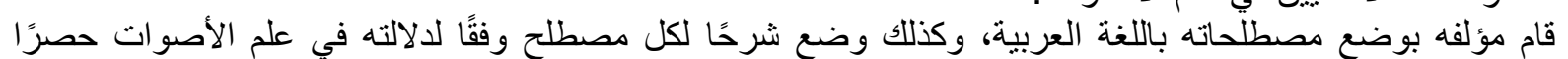

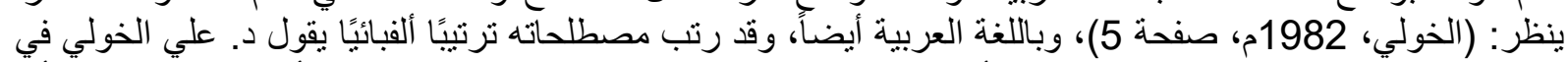

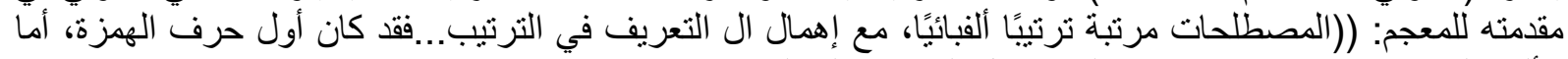

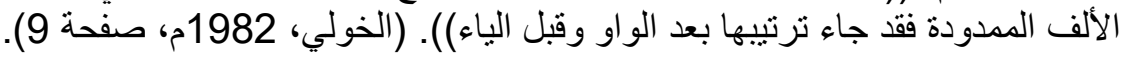

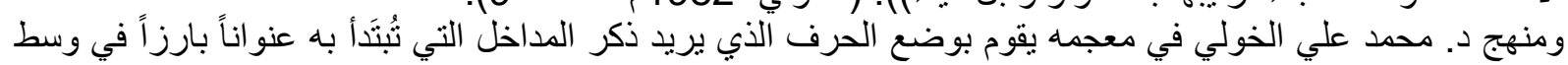

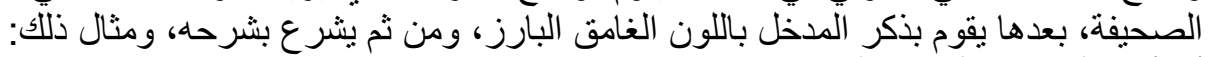

أـالأبجدية الصوتية الدولية:

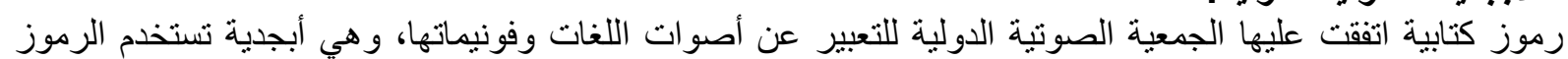

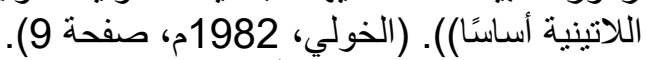

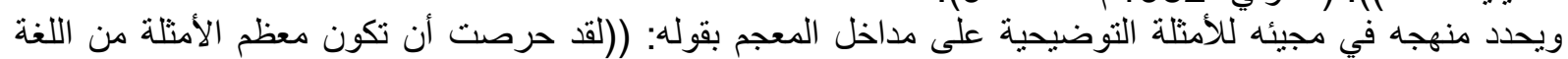

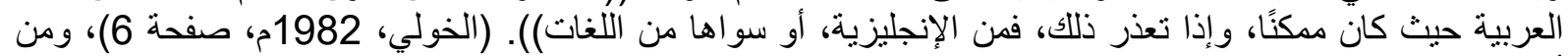

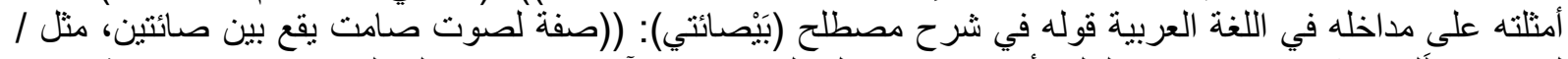

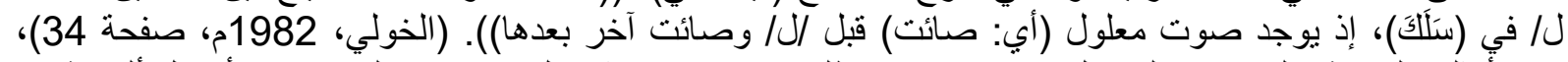

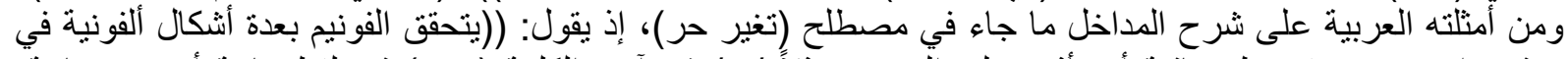

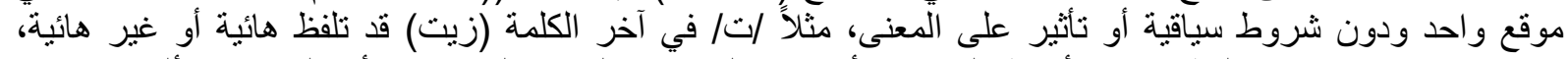

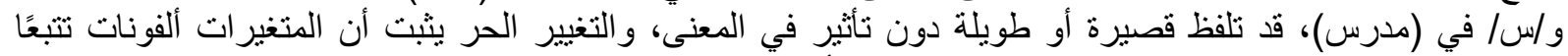

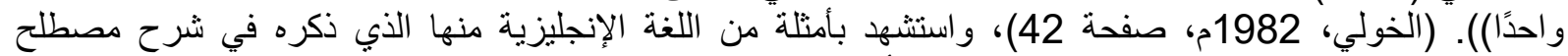

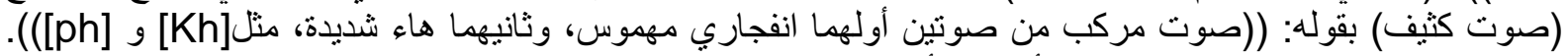

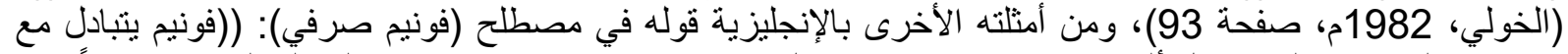

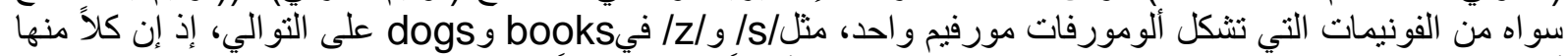

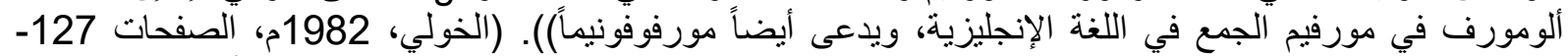
128)، ونجده يستخدم الخطين المائلين / / للدلالة على الفونيم، الإنيز، و القوسين المعقوفين ] [ للدلالة على الألوفون. (الخولي،

(6) 1982م، صفحة 1982) لم يضع د. الخولي مسردًا في نهاية معجمه، كون معهد معجمه أحادي اللغة، فلا حاجة للمسارد التي غالباً ما تكون الحاجة إليها

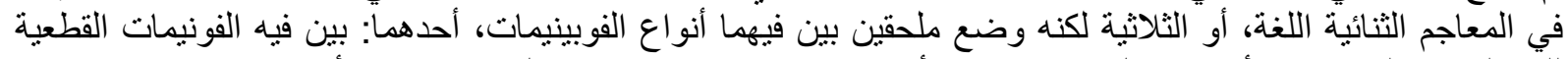

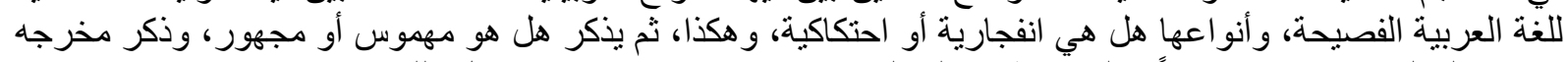

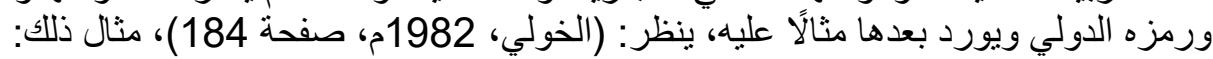




\begin{tabular}{|c|c|c|c|c|c|c|}
\hline مثال & الدولي & مخرجه & مجهوس أو & نو عه & الفونيم & الرقم \\
\hline تلا & $\mathrm{t}$ & أسناني & مهموس & انفجاري & ت & 1 \\
\hline طار & $\mathrm{T}$ & مطنيق & مهموس & انفجاري & b & 2 \\
\hline
\end{tabular}

وملحقاً آخر بين فيه الفونيمات القطعية في اللغة الإنجليزية، ينظر: (الخولي، 1982م، صفحة 186)، ومثاله:

\begin{tabular}{|c|c|c|c|c|c|}
\hline مثال & مخرجه & مجهور أو & نو عه & الفونيم & الرقم \\
\hline pin & شفتاني & مهموس & انفجاري & $P$ & 1 \\
\hline Ban & شفتاني & مجهور & انفجاري & $B$ & 2 \\
\hline $\tan$ & لثوي & مهموس & انفجاري & $\mathrm{T}$ & 3 \\
\hline Dine & لثوي & مجهور & انفجاري & D & 4 \\
\hline
\end{tabular}

2- معجم تحليل الخطاب، باتريك شارودو - ودومينيك منغتو.

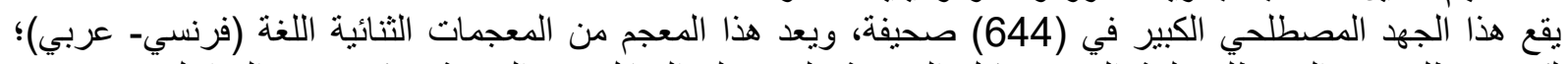

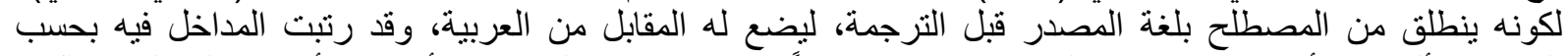

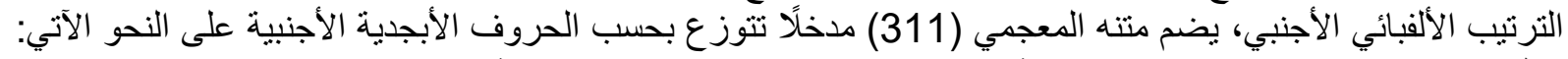

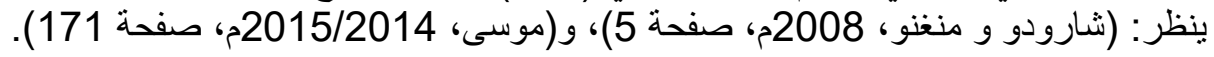

\begin{tabular}{|r|r|r|r|r|r|r|r||r|r||}
\hline $\mathrm{A}$ & $\mathrm{B}$ & $\mathrm{C}$ & $\mathrm{D}$ & $\mathrm{E}$ & $\mathrm{F}$ & $\mathrm{G}$ & $\mathrm{H}$ & $\mathrm{I}$ & $\mathrm{G}$ \\
\hline 33 & 00 & 38 & 20 & 30 & 11 & 07 & 04 & 22 & 00 \\
\hline $\mathrm{K}$ & $\mathrm{L}$ & $\mathrm{M}$ & $\mathrm{N}$ & $\mathrm{O}$ & $\mathrm{P}$ & $\mathrm{Q}$ & $\mathrm{R}$ & $\mathrm{S}$ & $\mathrm{T}$ \\
\hline 00 & 13 & 20 & 02 & 04 & 37 & 01 & 18 & 29 & 14 \\
\hline \hline $\mathrm{U}$ & $\mathrm{V}$ & $\mathrm{W}$ & $\mathrm{X}$ & $\mathrm{Y}$ & $\mathrm{Z}$ & & & $\mathrm{d}$ \\
\hline 03 & 05 & 00 & 00 & 00 & 00 & & & $\mathrm{r}$ & 311 \\
\hline
\end{tabular}

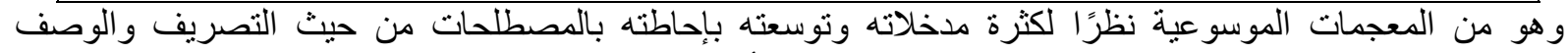

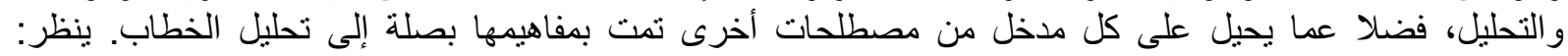

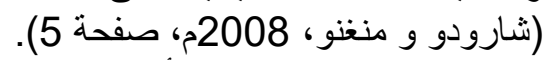

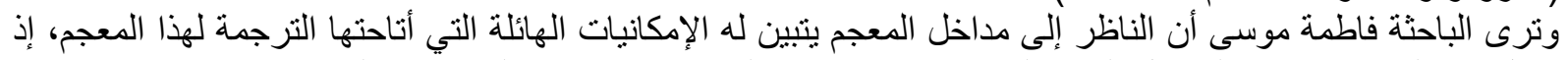

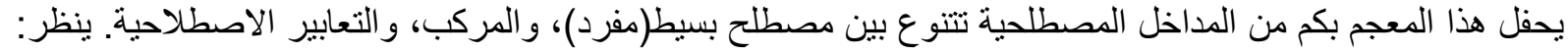
(موسى، 2015/2014م، صفحة 181 1812).

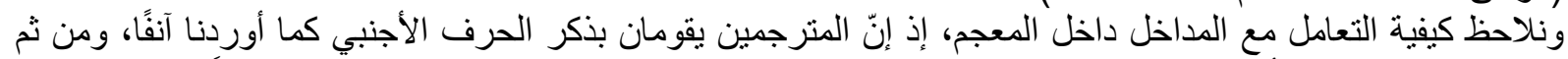

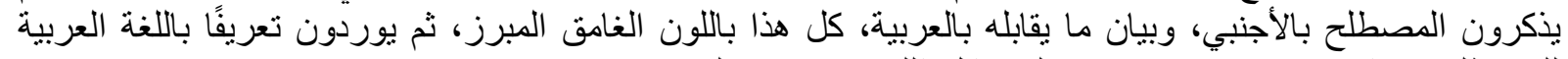

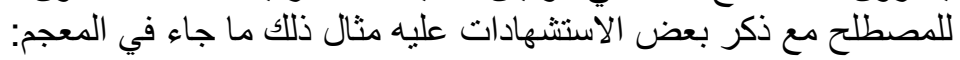

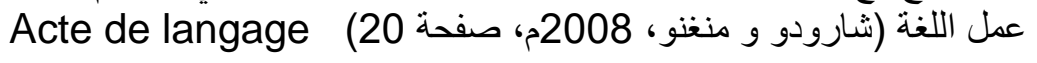




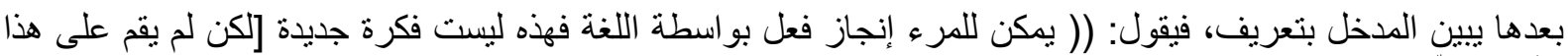

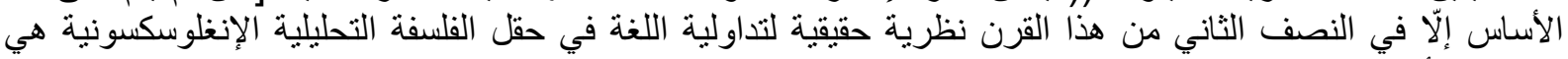

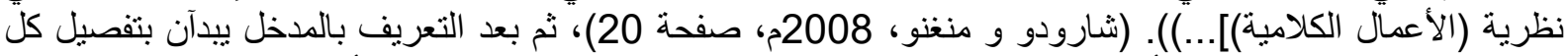

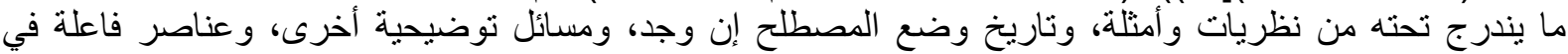

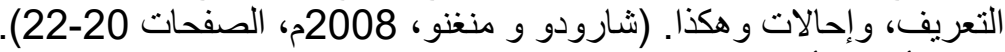

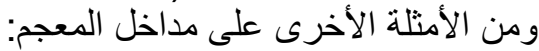

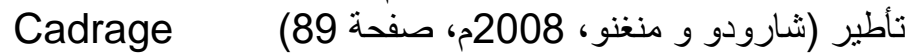

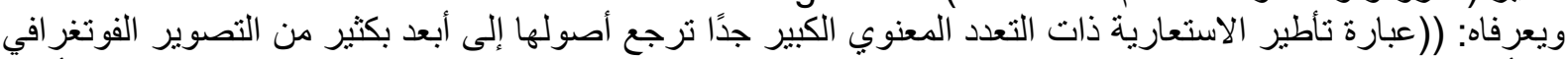

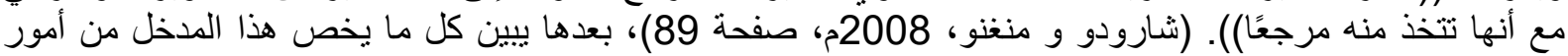

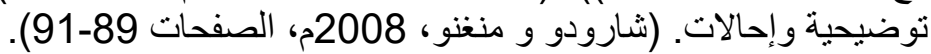

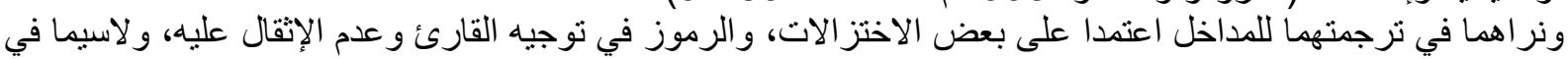

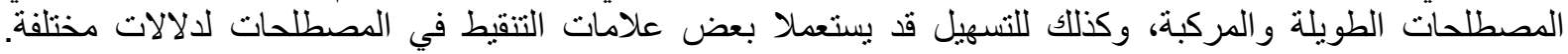

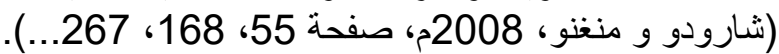

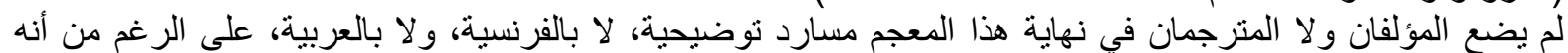

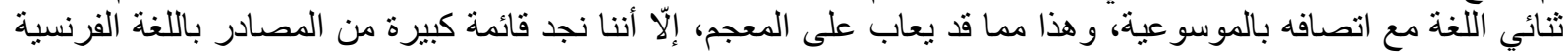

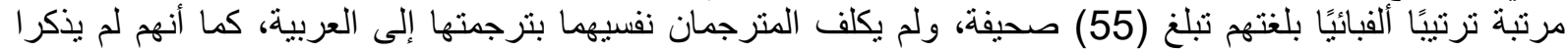

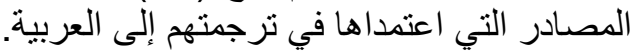

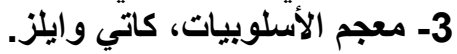

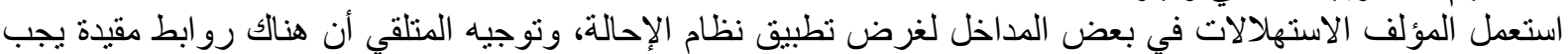

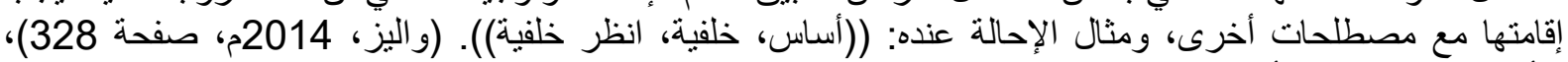

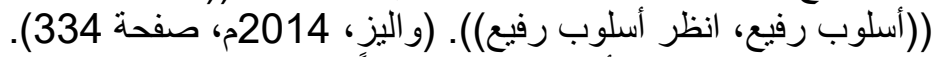

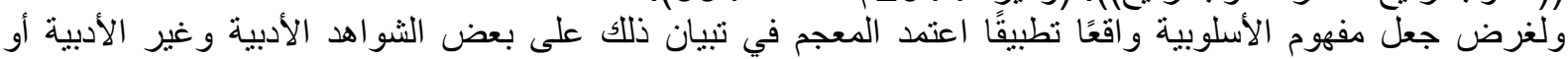

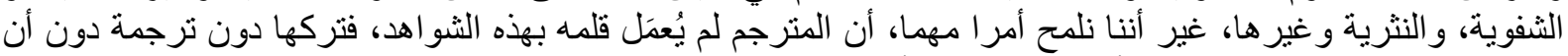

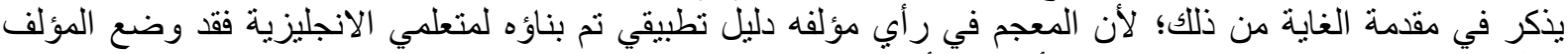

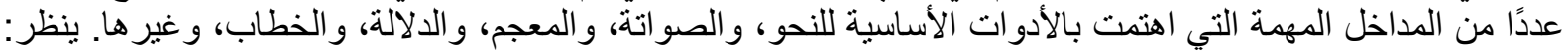

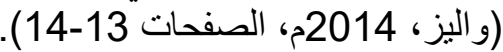
اهتم المؤلف واجتهد في إضافة بعض الأدوات التي تساعد في تسهيل عمله، ومنها: أنه أثبت ثنتين في خاتمة عمله:

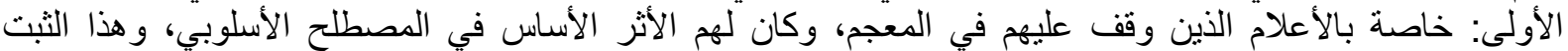

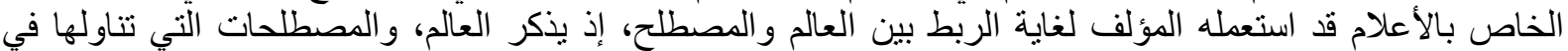

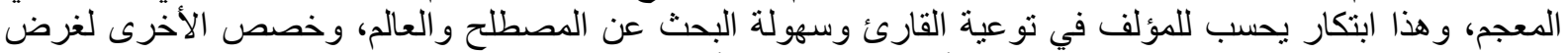

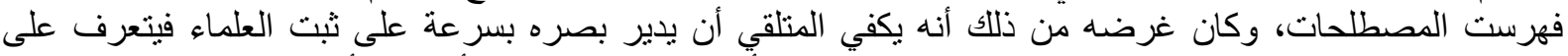

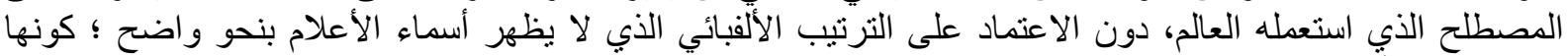

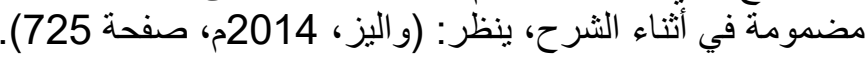

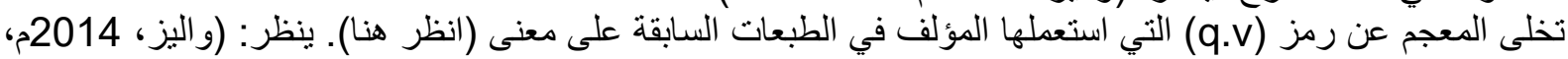

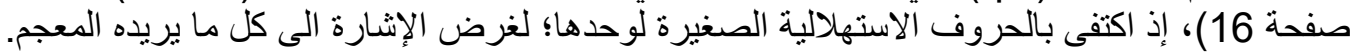

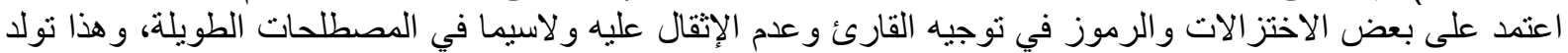

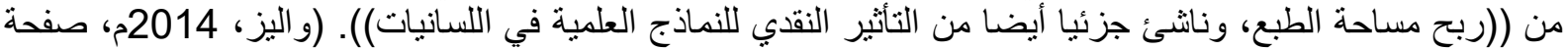

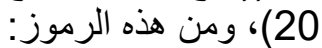

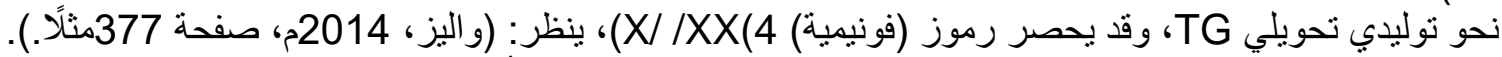

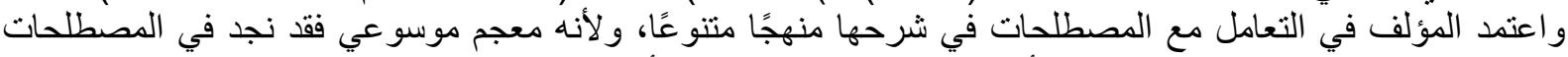

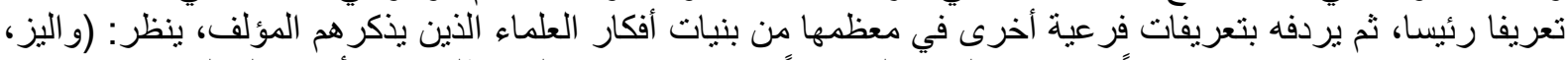

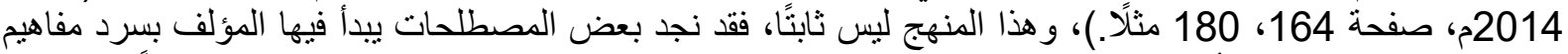

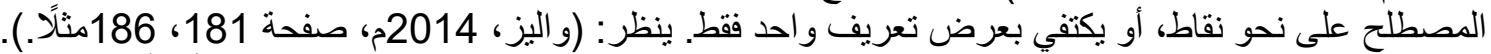

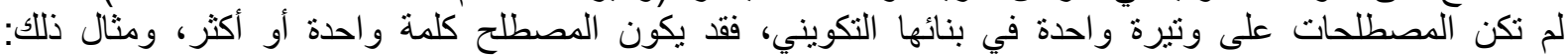

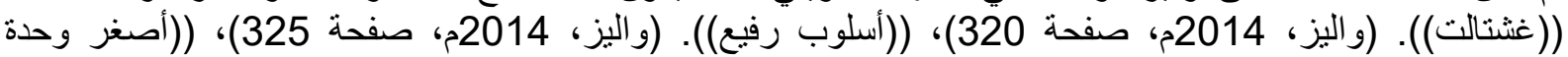
كتابية، علم در اسة الكتابة، وظيفة كتابية...)). (و اليز، (2014)، 2014م، صفحة (2014) (326).

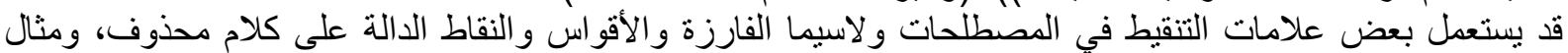
ذلك: (لسان مجموعة (لهجة محلية، المصطلح الاصطلاحية)). (واليز، 2014م، صفحة 253)، ((قرينة، 
قرائن...إلخ)). (واليز، 2014م، صفحة 368)، وقد تتعدد المصطلحات للمترجم، فلا يقابلها سوى مصطلح انجليزي

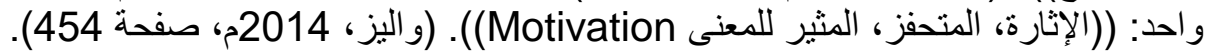

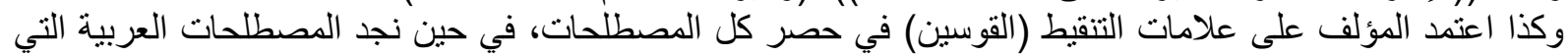

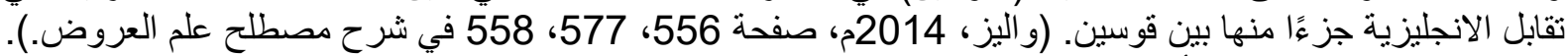

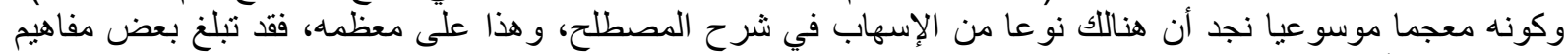

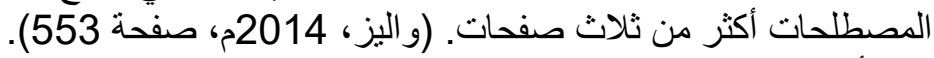

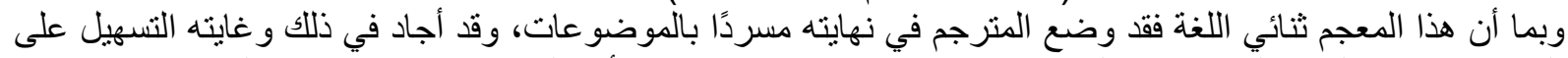

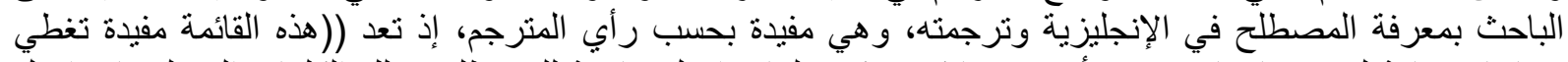

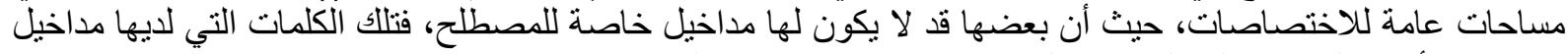

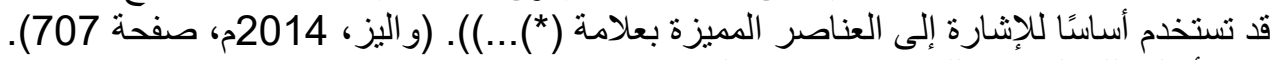
*(Conversation Analysis) (CA)

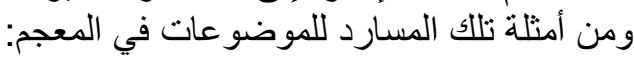

زوج مناخمة (CAdjacency Pair) إغلاق، (Cosing) (تغريب، - (Estrange)

تحليل التحاور

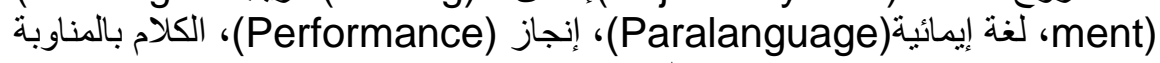

(Tur-Taking) (و اليز، 2014م، صفحة (P08).

${ }^{*}$ (Structuralism)

(Bifference)

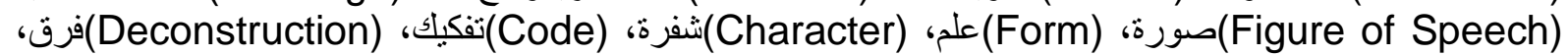

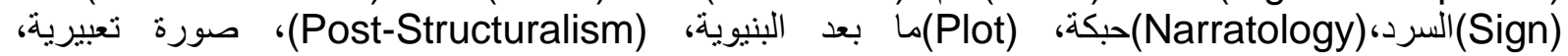

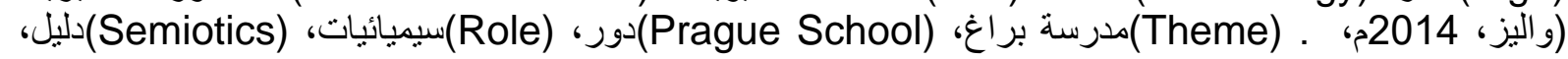

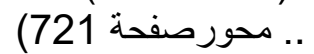

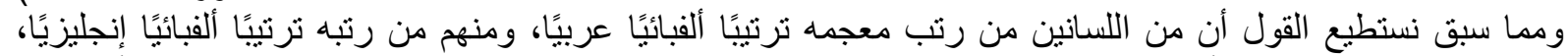

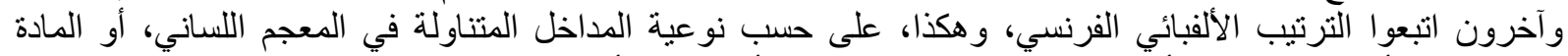

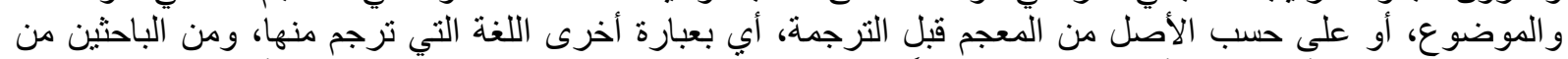

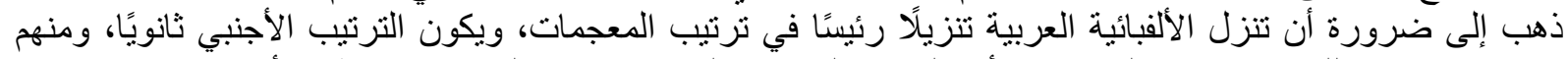

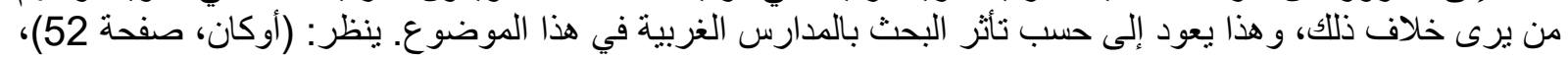

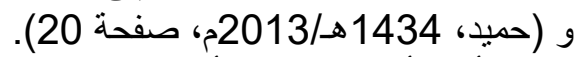
ونرى أن الأولى اعتماد الألفبائية العربية؛ لما في ذلك من تسهيل على من يتناول المعجم من الباحثين العرب، ولتكون للغنتا الدور الأبرز بين اللغات في مثل هكذا أعمال.

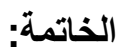

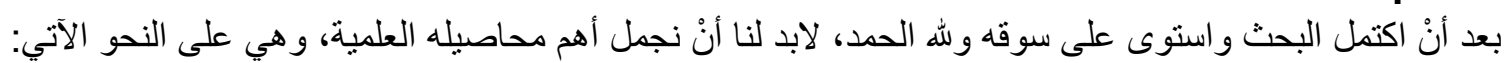

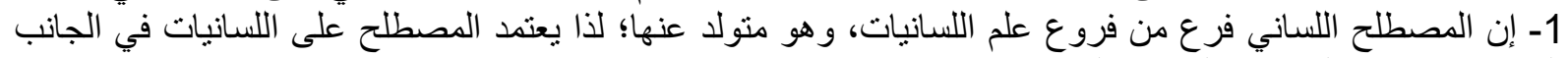
التطبيقي خاصة، الذي منه الدراسة المعجمية.

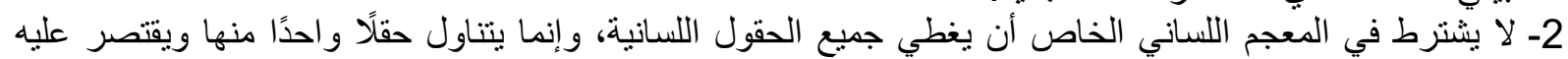

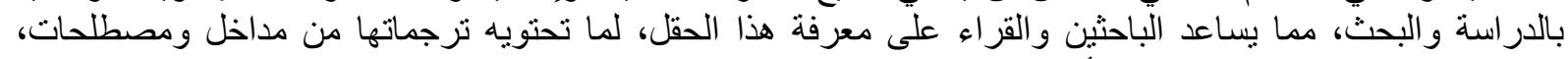

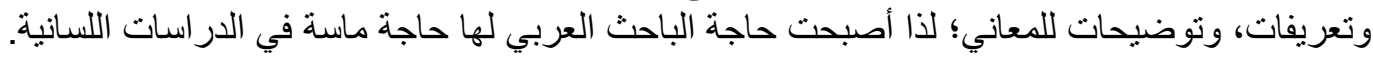

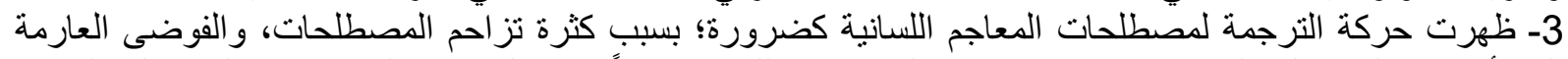

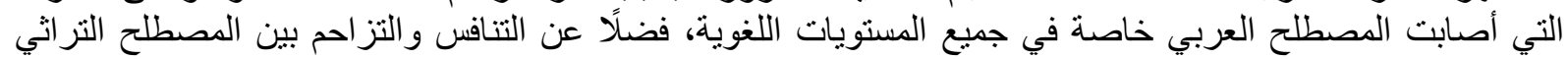
القديم، والحديث. 4- يعد معجم علم الأصوات الذي ألفه د. الخولي من المعجمات العربية الني صبت جلت جل الهتماماتها على علم الأصوات

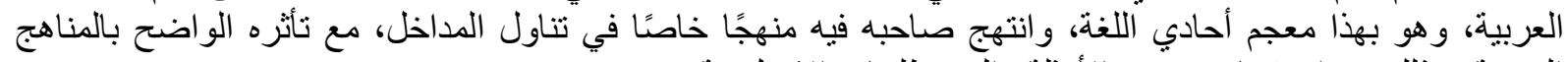

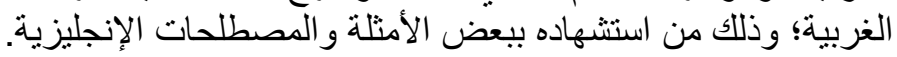

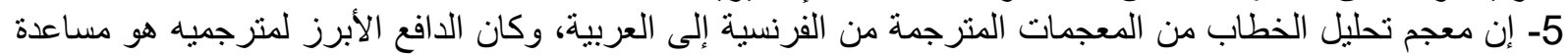

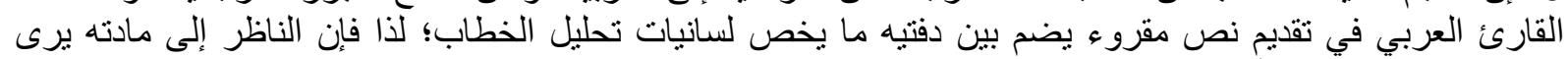

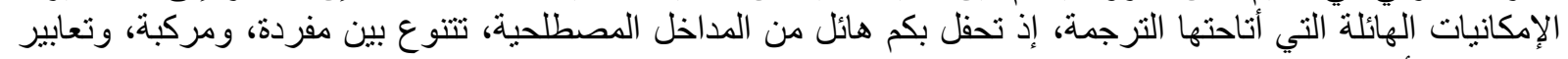

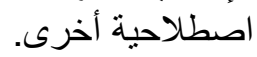
6- من المعجمات المترجمة من الإنجليزية إلى العربية معجم الأسلوبيات، كان الدافع من ترجمتهاء أن يكون موسوعة تاريخية تضم بين جناحيها مصطلحات الحقل اللساني الأسلوبي، وليكون مرجعًا في الأسلوبيات. 
ولعلنا بهذا القدر مما ذكرنا من نتائج يكفي؛ لإظهار أهمية المعاجم المصطلحية اللسانبة الخاصة، ونكون قد وضعنا غرساً

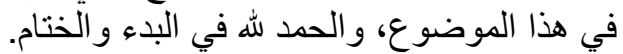

إبراهيم مر اد. (1986م). 14- المشاكل المنهجية في نقل المصطلح العلمي الأعجمي إلى العربية، تطبيق على معجم

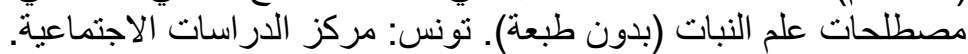

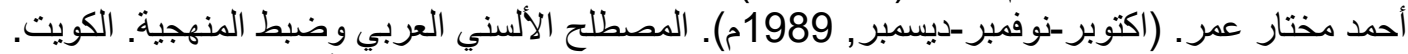

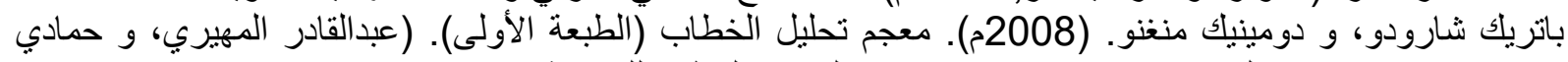

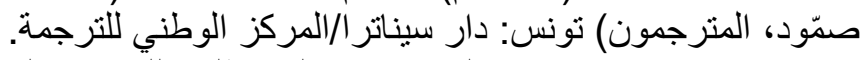

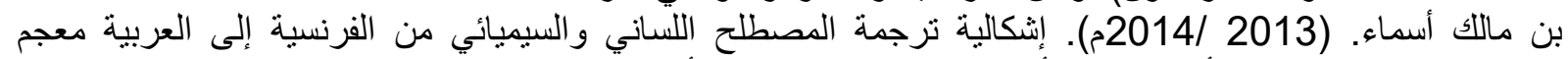
(المجيب) لأحمد العايد أنموذجًا. الجزائر: جامعة أبي بكر بلقايد تلمسان كلية الآداب واللغات المات رسالة

$$
\text { ماجستير غير منشورة. }
$$

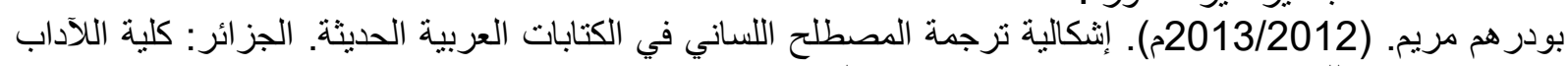

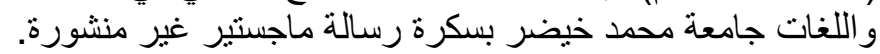

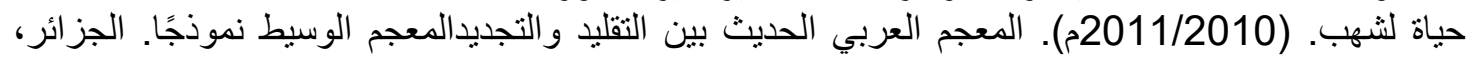

سطيف: كلبة الآداب و اللغات جامعة فرحات عباس رسالة ماجستير غير الفير منشورة.

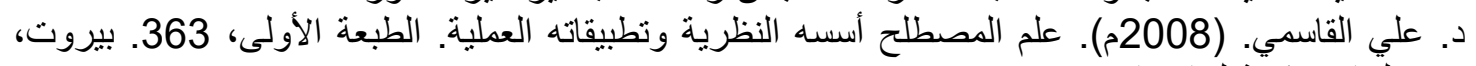
لبنان: مكتبة لبنان ناشرون.

د.بشير إبرير. (مارس, 2011م). علم المصطلح وأثره في بناء الخطاب اللساني العربي الحديث. مجلة اللسانيات و اللغة د.خليفة الميساوي. (1434 هـ/2013). العربية. المصطلح اللساني وتأسيس المفهوم (الطبعة الأولى). المغرب، الرباط: دار

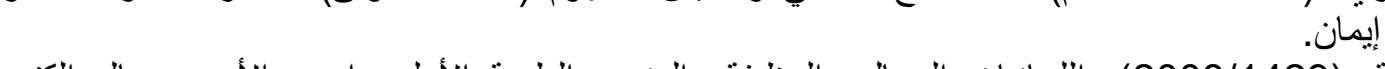

د.سمير استيتية. (2008/1429). اللسانيات المجال و الوظيفة والمنهج. الطبعة الأولى. إربد، الأردن: عالم الكتب الحديث.

د.عمار ساسي. (1434هـ/2002م). الدصطلح في اللسان العربي من آلية الفهم إلى أداة الصناعة. الطبعة الأولى.

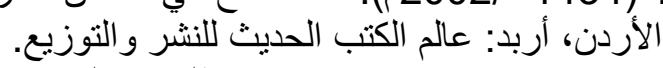

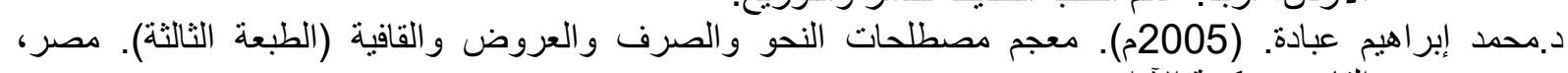

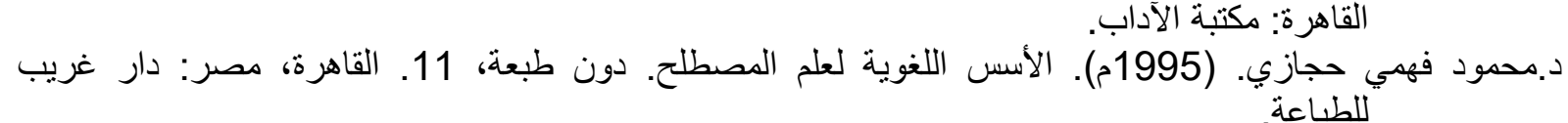

د.نور الهدى لوشن. (2001م). مباحث في علم اللغة ومناهج البحث اللغوي. الاسكندرية، مصر : المكتبة الجامعية.

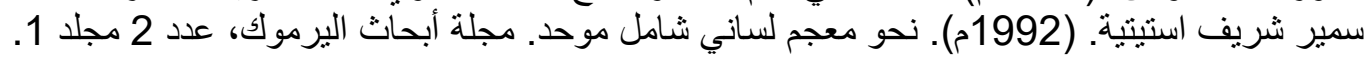

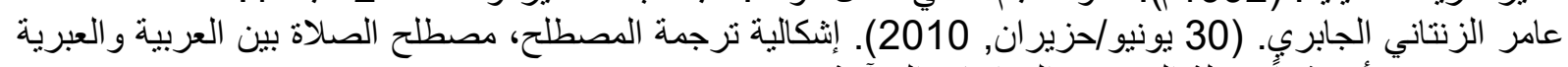

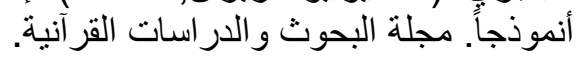

علي القاسمي. (1411هـ/1991م). علم اللغة وصناعة الناعة المعجم (الطبعة الثنانية). الرياض، السعودية: عمادة شؤون المكتبات جامعة الملك سعود.

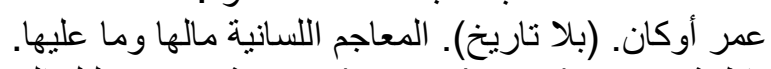

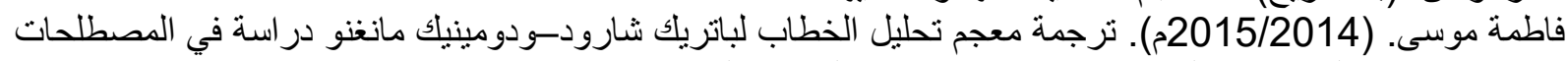

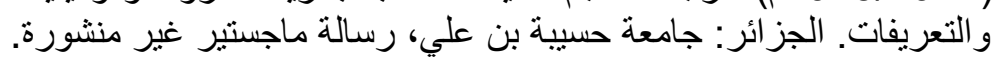

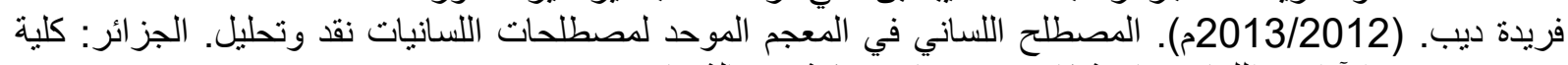

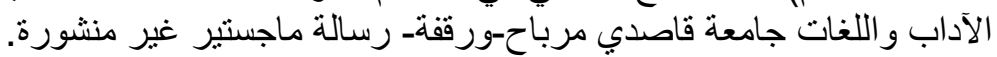

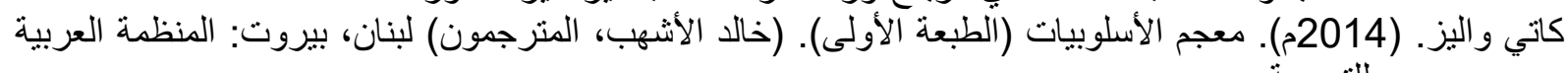
ل اللترجمة.

محمد علي الخولي. (1982م). معجم علم الأصوات (الطبعة الأولى). السعودية، الرياض: مطابع الفرزدق التجارية.

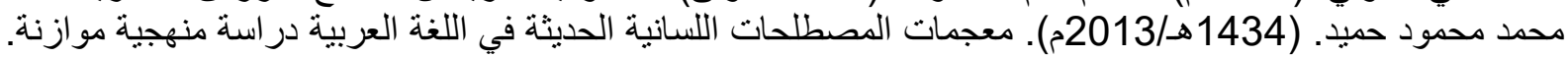

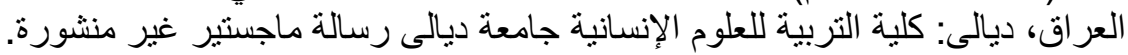

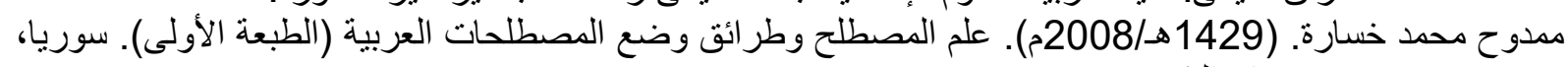
دمشق: دار الفكر. 
وجدي رزق غالي، و حسين نصار. (1971م). المعمات العربية بيلوغر افيا شاملة ومشروحة (بدون طبعة). مصر، القاهرة: الهيئة المصرية العامة للتأليف و النشر.

وليد محمد السر اقبي. (شتاء, 2012). الترجمة المشوهة ولئة وفوضى المصطلح اللساني. مجلة المنظمة العربية للترجمة. 